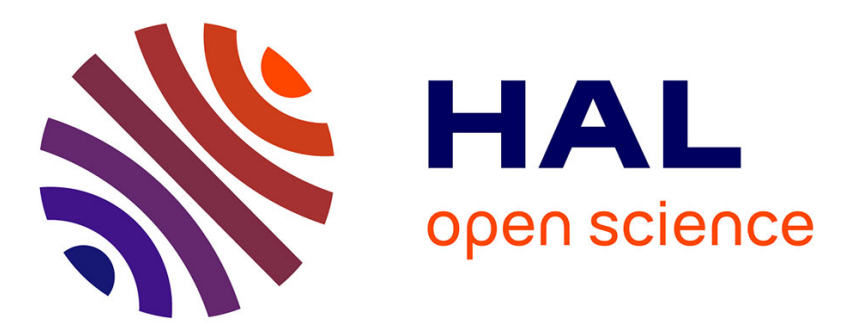

\title{
Elastic strain induced abnormal grain growth in graphene nanosheets (GNSs) reinforced copper $(\mathrm{Cu})$ matrix composites
}

Hailong Shi, Weimin Gan, Claude Esling, Xiaojun Wang, Y. D. Zhang, Emad Maawad, Andreas Stark, Xiaohu Li, Lidong Wang

\section{To cite this version:}

Hailong Shi, Weimin Gan, Claude Esling, Xiaojun Wang, Y. D. Zhang, et al.. Elastic strain induced abnormal grain growth in graphene nanosheets (GNSs) reinforced copper $(\mathrm{Cu})$ matrix composites. Acta Materialia, 2020, 200, pp.338-350. 10.1016/j.actamat.2020.09.017 . hal-03079707

\section{HAL Id: hal-03079707 \\ https://hal.univ-lorraine.fr/hal-03079707}

Submitted on 17 Dec 2020

HAL is a multi-disciplinary open access archive for the deposit and dissemination of scientific research documents, whether they are published or not. The documents may come from teaching and research institutions in France or abroad, or from public or private research centers.
L'archive ouverte pluridisciplinaire HAL, est destinée au dépôt et à la diffusion de documents scientifiques de niveau recherche, publiés ou non, émanant des établissements d'enseignement et de recherche français ou étrangers, des laboratoires publics ou privés. 


\title{
Elastic strain induced abnormal grain growth in graphene nanosheets (GNSs) reinforced copper $(\mathrm{Cu})$ matrix composites
}

\author{
Hailong Shi a,b,c,e, Weimin Gan ${ }^{\text {c }}$, Claude Esling b,e,*, Xiaojun Wang a, ${ }^{\text {a,** }}$, Yudong Zhang b,e, Emad Maawad d , Andreas \\ Stark ${ }^{\mathrm{d}}$, Xiaohu Li ${ }^{\mathrm{c}}$, Lidong Wang a

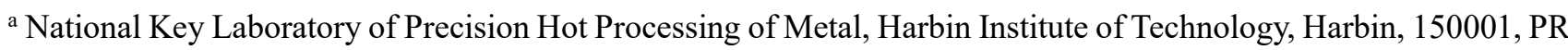 \\ China \\ ${ }^{\mathrm{b}}$ Université de Lorraine, CNRS, Arts et Métiers ParisTech, LEM3, F-57070, Metz, France \\ c GEMS at Heinz Maier-Leibnitz Zentrum (MLZ), Helmholtz-Zentrum Geesthacht, Lichtenbergstr. 1, D-85748 \\ Garching, Germany \\ ${ }^{\mathrm{d}}$ Institute of Materials Research, Helmholtz-Zentrum Geesthacht, Max-Planck-Str. 1, D-21502 Geesthacht, Germany \\ ${ }^{\mathrm{e}}$ Laboratory of Excellence on Design of Alloy Metals for low-mAss Structures (DAMAS), Université de Lorraine, \\ F-57070, Metz, France
}

\begin{abstract}
Orientation related grain growth stimuli during primary and secondary recrystallization of the metal matrix in laminated metal/non-metal composites demonstrate unique effect on orientation evolution but has rarely been investigated. In this work, the recrystallization and grain growth of $\mathrm{Cu}$ in a graphene nanosheets (GNSs) reinforced laminated $\mathrm{Cu}$ matrix composite during sintering was thoroughly investigated. The microstructure, texture and lattice strain evolution of the $\mathrm{Cu} / \mathrm{GNS}$ composite was examined referenced to the $\mathrm{Cu}$ stack without GNSs by ex-situ and in-situ orientation characterization techniques (SEM-EBSD, neutron diffraction and synchrotron radiation) from mesoscale to macroscopic scale. The results evidenced that a strong Cube orientation was produced in the $\mathrm{Cu} / \mathrm{GNS}$ composite instead of the individual non-Cube orientations in the pure $\mathrm{Cu}$ stack without GNSs. Detailed strain-state analysis of the $\mathrm{Cu}$ foils in the $\mathrm{Cu} / \mathrm{GNS}$ composite revealed that the anisotropic expansion behavior of the GNS that is incompatible with that of the $\mathrm{Cu}$ foils imposed multiple elastic constraints to the foils during the sintering process, resulting in a biaxial isostrain state in the surface layers and a uniaxial compressive strain state in the central layer of each $\mathrm{Cu}$ foil. The elastic anisotropy of $\mathrm{Cu}$ favors the growth of the Cube oriented grains to minimize the total strain energy. This work clarified the thermal strain induced abnormal grain growth of selected orientations. The mechanism revealed can be useful for analysing abnormal grain growth in elastically strained materials and can also be applied to fabrication process for texturization or even monocrystallization.
\end{abstract}


Keywords: Texture; Recrystallization; Abnormal grain growth; Anisotropic elasticity; Metal matrix composite.

\section{Introduction}

Recrystallization and grain growth are intrinsic processes of metallic materials occurring inevitably when the material is thermally treated after plastic deformation. The driving force arises from the high stored energy in relation to the point defects, dislocations and grain boundaries created during the deformation process [1-4]. Recrystallization makes drastic microstructure and crystallographic texture transformation of the deformed materials. Certain orientation related stimuli, such as orientation related surface energy, may cause abnormal grain growth and completely modify the recrystallized microstructure and texture [5-9]. As the microstructural and texture transformation significantly affect the properties of the materials, the determination and interpretation of recrystallization texture are of both fundamental and practical importance in materials processing. Thus, study on the origin of recrystallization and grain growth has been intensive for decades for the purpose of practical property control and theoretical microstructure process simulation. The related investigations were first conducted in mono-phased metals or alloy systems [4, 10-12]. The external influential factors, such as deformation amount, deformation temperature, material purity and initial grain size [13-15] have been always the subjects of investigtions. Two theories have been elaborated, the one being Oriented Nucleation (ON) and the other Oriented Growth (OG) [16-18].

With the demand on materials capacity for wide applications, composite materials integrating suitably distributed two or several chemically and physically distinct constituent components were conceived to provide properties not obtainable from any of the single components. According to the nature of the components, the composite could be classified into two categories, i.e., metal $/ \mathrm{metal}$ and metal/non-metal composites. For the former, one of the representative composites are the laminar metal composites (LMCs) usually fabricated by serve plastic deformation (SPD) techniques like Accumulative Roll Bonding (ARB) [19-21] and Repeated Folding and Rolling [22, 23]. For the latter, non-metal reinforcements such as ceramic particles ( $\mathrm{SiC}, \mathrm{Al}_{2} \mathrm{O}_{3}$, TiC, etc. [24, 25]), short whiskers and fibers ( $\mathrm{TiB}, \mathrm{Al}_{2} \mathrm{O}_{3}-\mathrm{SiO}_{2}$, $\mathrm{SiC}$, etc. [26, 27]) and continuous fibers (carbon fiber, W, B, etc. [28, 29]) are usually adopted. Recently, carbon materials (graphite, carbon nanotubes and graphene) received great 
attention as ideal reinforcements for metal matrix composites because of their superior mechanical and physical properties [30, 31]. For the metal/metal LMCs, the recrystallization and grain growth processes have been intensively investigated by the ex-situ and in-situ electron back-scattered diffraction (EBSD) and transmission electron microscopic (TEM) characterization. The creation and redistribution of dislocations, grain boundaries, and phase boundaries during the $\mathrm{ARB}$ and the subsequent annealing process have been thoroughly investigated. For the metal/non-metal composites, the recrystallization and grain growth processes happening inevitably during sintering are more complicated. On the one hand, the different thermal expansion coefficients (TEC) of the non-metal reinforcement from those of the matrix metal introduces giant thermal constraints to the recrystallization and grain growth process of the metal matrix. On the other hand, the non-metal reinforcements are much finer. A huge thickness difference exists between the matrix metal and the non-metal reinforcements. Thus, the effect of the non-metal reinforcements subsides with the distance into the metal matrix. The constraints are more in a gradient form, further complicating their influence on the recrystallization and grain growth of the metal matrix. So far, the effect of the reinforcements on the recrystallization and grain growth of the metal matrix has rarely been investigated and stays unclear.

Motivated by such an observation, we conducted the present work. The composite components used are cold-rolled $\mathrm{Cu}$ foils with a thickness of $30 \mu \mathrm{m}$ and multi-layered graphene nanosheets (GNSs) each with a diameter of 1-3 $\mu \mathrm{m}$ and a thickness of 1-5 $\mathrm{nm}$ that were deposited on the $\mathrm{Cu}$ surfaces. The asdeposited cold-rolled $\mathrm{Cu}$ foils were stacked and hot-pressing sintered. The evolutions of the microstructure and orientation were first thoroughly examined through ex-situ orientation characterization techniques in multi-scales (SEM-EBSD and neutron diffraction). In particular, the advanced in-situ synchrotron radiation technique was used to characterize the complicated strain state by measuring the lattice strain of the $\mathrm{Cu}$ matrix during the recrystallization and grain growth processes. To reveal the underlying mechanism on selective grain growth, the experimental output was further analyzed in the frame of the elasticity theory. The results provide useful information for the theory of recrystallization and grain growth of metallic materials and helpful for analysing abnormal grain growth in elastically strained materials, such as structural products produced by additive fabrication. 
The stimulus for selective grain growth can be conceived to fabricate strongly textured or even monocrystallized materials.

\section{Experimental procedures}

\subsection{Material and sample preparation}

The materials used in this study are cold-rolled $\mathrm{Cu}$ foils with a thickness of about $30 \mu \mathrm{m}$ and the graphene nanosheets (GNSs) with specification thicknesses around 1 5 nm (the thickness of monolayer graphene is $0.34 \mathrm{~nm}$ ) that was further verified by Atomic Force Microscopy (AFM) analysis as detailed in Appendix A1). The chemical composition of the $\mathrm{Cu}$ foils is displayed in Table 1. The fabrication of the bulk composite with the two materials was through two steps: electrophoretic deposition (EPD) of the GNSs on the two surfaces of each $\mathrm{Cu}$ foil and hot-pressing sintering of the stacked $\mathrm{Cu}$ foils with the GNSs, as detailed below.

Table 1. Chemical composition of $\mathrm{Cu}$ foil (wt.\%).

\begin{tabular}{ccccccc}
\hline $\mathrm{Cu}$ & $\mathrm{Pb}$ & $\mathrm{Fe}$ & $\mathrm{Sb}$ & $\mathrm{S}$ & $\mathrm{As}$ & $\mathrm{Bi}$ \\
\hline $\mathbf{9 9 9 . 9 0}$ & $\leq \mathbf{0 . 0 0 5}$ & $\leq \mathbf{0 . 0 0 5}$ & $\leq \mathbf{0 . 0 0 2}$ & $\leq \mathbf{0 . 0 0 5}$ & $\leq \mathbf{0 . 0 0 2}$ & $\leq \mathbf{0 . 0 0 1}$ \\
\hline
\end{tabular}

The electrophoretic deposition (EPD) process was conducted in an electrolytic cell. A pure Cu plate of $50 \times 50 \times 5 \mathrm{~mm}^{3}$ was employed as the anode and the cold-rolled $\mathrm{Cu}$ foils with the same sized surface area as the cathode. An electrolyte suspension solution with GNSs of $0.004 \mathrm{~g} \cdot \mathrm{mol}^{-1}$ was utilized and the distance between the two electrodes was $50 \mathrm{~mm}$. The deposition on each $\mathrm{Cu}$ foil was conducted at $30 \mathrm{~V}$ for $30 \mathrm{~s}$. The coverage of the GNSs on the $\mathrm{Cu}$ foil surfaces was estimated, as detailed in Appendix A1. After deposition, the as-deposited $\mathrm{Cu}$ foils were dried in air and stored in a vacuum tank for the subsequent stacking and hot-pressing sintering. For comparison, the $\mathrm{Cu}$ foils without the deposition of the GNSs were also prepared. $100 \mathrm{Cu}$ foils each with an area of $4 \times 4 \mathrm{~mm}^{2}$ with and without the GNSs were further stacked to $3 \mathrm{~mm}$ thick bulks. The stacks were made along the direction normal to the foil plane, i.e., the normal direction (ND) in the orthonormal rolling coordinate system (the rolling direction (RD), the transverse direction (TD) and the ND) by keeping the respective RD and TD consistent for each foil. The stacks with the GNSs were denoted $\mathrm{Cu} / \mathrm{GNS}$ and the stacks without the GNSs pure $\mathrm{Cu}$. The hot-pressing sintering process of the $\mathrm{Cu} / \mathrm{GNS}$ composite and the pure $\mathrm{Cu}$ was 
identically conducted in vacuum $\left(<10^{-2} \mathrm{~Pa}\right)$ under a compressive stress of about $50 \mathrm{MPa}$ applied along the ND. The stacks were first heated to $950{ }^{\circ} \mathrm{C}$ at a rate of about $5{ }^{\circ} \mathrm{C} \cdot \mathrm{min}^{-1}$, isothermally held for 2 hours and then cooled inside the furnace to room temperature.

In order to study the influences of the GNSs on the microstructure and texture evolution during the sintering process by SEM-EBSD for the former and by neutron diffraction measurements for the latter, the as-deposited $\mathrm{Cu} / \mathrm{GNS}$ samples and the pure cold-rolled $\mathrm{Cu}$ samples were sintered to $150{ }^{\circ} \mathrm{C}, 170^{\circ} \mathrm{C}$, $230{ }^{\circ} \mathrm{C}, 450{ }^{\circ} \mathrm{C}$ and $700{ }^{\circ} \mathrm{C}$, respectively, in a dilatometer (DIL 805A/D), and then quenched in compressed argon flux to room temperature to preserve the as-heated microstructure.

\subsection{Microstructural characterization and texture analysis}

Microstructural features of the pure $\mathrm{Cu}$ and the $\mathrm{Cu} / \mathrm{GNS}$ samples at the states of as-cold-rolled, asfully-sintered and as-heated to different temperatures were characterized by scanning electron microscopy - electron backscatter diffraction (SEM-EBSD), using a JEOL 6500F SEM equipped with an EBSD acquisition camera and the Aztech online acquisition software package (Oxford Instruments). In order to achieve the surface quality required for EBSD measurement, the samples were mechanically polished with grit silicon carbide wet sandpaper up to \#4000, and then electro-polished with a solution of $20 \%$ nitric acid and $80 \%$ methanol at a temperature lower than $15{ }^{\circ} \mathrm{C}$ under a voltage of $10 \mathrm{~V}$ for $5 \mathrm{~s}$. The EBSD measurements were performed under the beam controlled mode with a step size of $70 \mathrm{~nm}$ for the as-cold-rolled and the as-heated samples and of $0.35 \mu \mathrm{m}$ for the as-sintered samples. The measurement results were analyzed with the Channel 5 (Oxford Instruments) and homemade ATEX [32] software packages.

The bulk texture of the pure $\mathrm{Cu}$ and the $\mathrm{Cu} / \mathrm{GNS}$ samples at the states of as-cold-rolled, as-fullysintered and as-heated to different temperatures were measured by neutron diffraction at the diffractometer STRESS-SPEC located at FRM II (Heinz Maier-Leibnitz Zentrum (MLZ), Garching, Germany). The PG (200) monochromator was selected to produce neutrons with a dual-wavelength of 1.11 and $1.65 \AA$. The (111), (220) and (200) diffraction patterns were recorded at $2 \theta=51^{\circ}$ with a detector window of $15^{\circ}$. The software StressTextureCalculator (SteCa2-2.0) [33] was used to extract the pole figure intensity data.

2.3 In-situ synchrotron radiation measurement 
In order to examine the lattice strain evolution during the sintering process, the in-situ high energy X-ray diffraction (HEXRD) experiments were performed at the P07-HEMS beamline operated by the Helmholtz-Zentrum Geesthacht at PETRA III (Deutsches Elektronen-Synchrotron (DESY), Hamburg Germany), using a DIL805A/D dilatometer [34]. The main experimental parameters of the HEXRD setup are summarized in Table 2. The instrument calibration was performed using a standard $\mathrm{LaB}_{6}$ powder sample. During the measurement, the as-cold-rolled pure $\mathrm{Cu}$ sample and $\mathrm{Cu} / \mathrm{GNS}$ composite samples each was heated from the ambient temperature $\left(<28{ }^{\circ} \mathrm{C}\right)$ to $950{ }^{\circ} \mathrm{C}$ at a heating rate of $5^{\circ} \mathrm{C} \cdot \mathrm{min}^{-1}$, then cooled in an argon atmosphere. The incident beam was set to be parallel to the TD of the cold-rolled $\mathrm{Cu}$ foils. The geometrical configuration of the measurement layout is illustrated in Fig. 1. During the whole heating process, the full Debye-Scherrer rings were recorded at every 8 seconds. The measured 2D Debye-Scherrer patterns were processed using the FIT-2D [35] by which the DebyeScherrer rings were integrated radially at selected azimuthal angles to yield the $1 \mathrm{D}$ diffraction patterns that were further analyzed using a homemade program, A-fit. The information contained in the peak profile, such as the integrated intensity (I), the Bragg angles $(2 \theta)$ of the peaks and the full width at half maximum (FWHM) at each measured temperature were extracted.

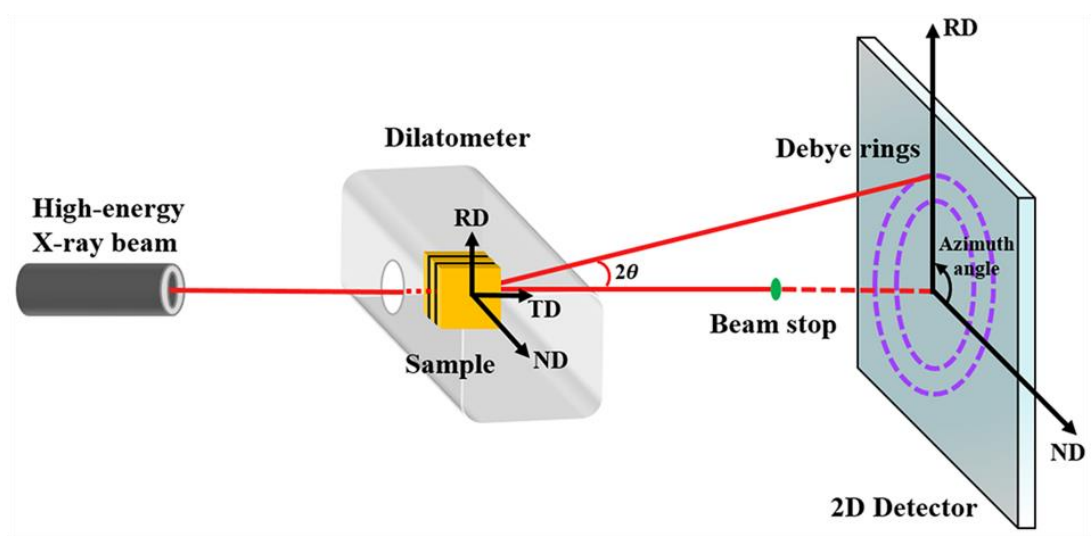

Fig. 1. Schema of in-situ synchrotron radiation measurement.

Table 2. Experimental parameters and devices of in-situ synchrotron radiation measurement.

\begin{tabular}{ccccccc}
\hline $\begin{array}{c}\text { Energy } \\
{[\mathrm{keV}]}\end{array}$ & $\begin{array}{c}\text { Wavelength } \\
{[\AA]}\end{array}$ & $\begin{array}{c}\text { Beam size } \\
{\left[\mathrm{mm}^{2}\right]}\end{array}$ & $\begin{array}{c}\text { Sample-Detector } \\
\text { Distance }[\mathrm{mm}]\end{array}$ & $\begin{array}{c}\text { Acquisition } \\
\text { time }[\mathrm{s}]\end{array}$ & Detector & Dilatometer \\
\hline 103.3 & 0.12 & $0.8 \times 0.8$ & 1306.5 & 8 & $\begin{array}{c}\text { Perkin Elmer } \\
\text { XRD 1621 }\end{array}$ & DIL 805A/D \\
\hline
\end{tabular}

For the fitting of the diffraction peaks, a Voigt profile (Pseudo-Voigt function) that results from the 
convolution of the Gaussian and the Lorentzian profile was used to mimic the exact Voigt function and to describe approximately both the instrumental and the intrinsic sample profiles. In order to subtract the instrumental broadening from the observed profile, an internal standard calibration technique was used in which a standard $\mathrm{LaB}_{6}$ powder sample (with a thickness of $5 \mathrm{~mm}$ in the beam direction) diffraction data was recorded under the identical experimental condition at room temperature. After that, the diffraction data for the standard $\mathrm{LaB}_{6}$ powder was calibrated by the Maud software package [36-39] to deduce the instrumental values so that the instrumental broadening could be excluded at different Bragg angles. It should be mentioned that the thickness of the $\mathrm{LaB}_{6}$ sample is very close to our pure $\mathrm{Cu}$ and $\mathrm{Cu} / \mathrm{GNS}$ composite samples $(4 \mathrm{~mm})$, thus, the shapes and the volumes of the $\mathrm{LaB}_{6}$ powder sample and our samples irradiated by the beam are very close and the effect from size difference should be largely eliminated. The integration of the raw Debye-Scherrer rings to the diffraction patterns was performed with the fit2D package, and the data from the $\mathrm{LaB}_{6}$ powder measurement was used to subtract the instrumental effect.

\section{Results}

\subsection{Initial microstructure and texture of as-cold-rolled $\mathrm{Cu}$ foil}

Fig. 2a displays an SEM-EBSD RD-axis inverse pole figure (RD-IPF) micrograph of the RD-ND plane of the as-cold-rolled $\mathrm{Cu}$ foil. It is seen that the cold-rolled $\mathrm{Cu}$ foil possesses banded microstructure composed of grains elongated in the $\mathrm{RD}$. The orientation of the deformed grains were further analyzed and represented with the respective texture component micrograph in Fig. 2b. It is clearly seen that the cold-rolled grains possess the Copper, the Brass, the Goss, the Cube and the S orientations that are the typical texture components of the cold-rolled FCC metals.

Fig. 2c shows the $\varphi_{2}=0^{\circ}, 45^{\circ}$ and $60^{\circ}$ sections of the orientation distribution function (ODF) of the cold-rolled foils measured by through-volume neutron diffraction. For reference, the ideal positions of the cold-rolled texture components are also indicated in the figure. It is seen from the measured ODF sections that macroscopically the texture of the present cold-rolled foils is also characterized by the five typical cold-rolled texture components: Copper, S, Brass, Goss and Cube, among which the Copper component is the strongest, the $\mathrm{S}$ the second and the Cube the weakest. Moreover, the Brass component spreads toward the Goss orientation along the $\alpha$ skeleton line $\left(\varphi_{2}=0^{\circ}\right.$ and $45^{\circ}$ sections $)$ and 
the Copper and the $\mathrm{S}$ components spread toward the Cube orientation $\left(\varphi_{2}=45^{\circ}\right.$ and $65^{\circ}$ sections $)$.
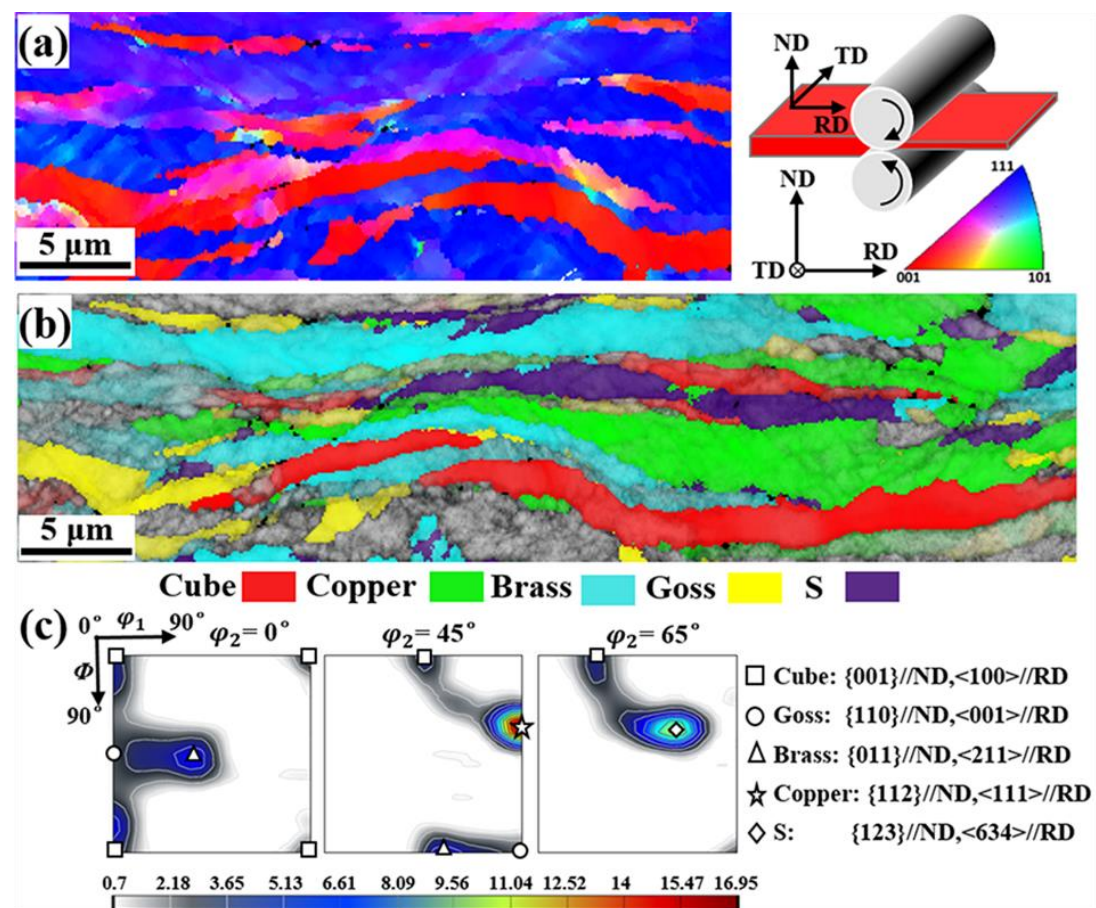

Fig. 2. Microstructure and texture of initial as-cold-rolled $\mathrm{Cu}$ foils. (a) SEM-EBSD RD inverse pole figure (RD-IPF) micrograph. (b) SEM-EBSD micrograph colored according to orientation of cold-rolled texture components of FCC metals. (c) Typical $\varphi_{2}=0^{\circ}, 45^{\circ}$ and $65^{\circ}$ sections of orientation distribution function (ODF) [40] measured by neutron diffraction (ideal texture components of cold-rolled FCC materials are detailed and indicated).

\subsection{Microstructure and texture of as-sintered pure $\mathrm{Cu}$ and $\mathrm{Cu} / \mathrm{GNS}$}

After sintering, the microstructures and textures in the two kinds of samples are in great contrast, although the initial banded structure in each $\mathrm{Cu}$ foil in both the pure $\mathrm{Cu}$ and the $\mathrm{Cu} / \mathrm{GNS}$ sample was replaced by fully recrystallized coarse grains, as shown in Fig. 3, the SEM-EBSD RD-IPF micrographs from the RD-ND plane of the as-fully-sintered multilayered pure $\mathrm{Cu}$ and $\mathrm{Cu} / \mathrm{GNS}$ samples together with the corresponding neutron diffraction ODF sections. For the pure $\mathrm{Cu}$ (Fig. 3a), it is composed of several coarse grains with the sizes in millimetre range and the texture is characterized by strong individual orientations. Although the microstructure of the pure $\mathrm{Cu}$ was obtained from the sample containing 100 layers of the cold-rolled foils, no layer interfaces can be identified within the coarse grains. The grain boundary migration during grain growth already overcame the confinement of the layer surfaces. However, for the $\mathrm{Cu} / \mathrm{GNS}$ composite, the microstructure is clearly layered and mainly composed of rectangular blocks delineated by the layer interfaces (the horizontal ones) where the 
GNSs were deposited and with the boundaries nearly perpendicular to the layer interfaces (the vertical ones). Moreover, most of the boundaries are low-angle boundaries $\left(<15^{\circ}\right.$, yellow lines in Fig. $\left.3 b\right)$. Although each block has its own distinct orientation, they are very close to the Cube orientation. Very occasionally, non-Cube oriented grains can be spotted (light to bright blue ones). Most of these grains are twin related with their neighbouring Cube oriented blocks and the boundaries between them are the $\Sigma 3$ coincident site lattice (CSL) boundaries. Such boundaries are less mobile [4], hence survived the abnormal growth of the Cube grains. The through-volume neutron diffraction ODF sections $\left(\varphi_{2}=\right.$ $0^{\circ}$ and $\left.45^{\circ}\right)$ in Fig. $3 \mathrm{~b}$ confirmed that in the whole measured sample volume $\left(4 \times 10 \times 2 \mathrm{~mm}^{3}\right)$ the Cube orientation is clearly dominant, thus, the microstructure displayed in Fig. $3 b$ is throughout the whole treated sample. The layered microstructure in the $\mathrm{Cu} / \mathrm{GNS}$ sample suggests that recovery, recrystallization and then the abnormal grain growth occurred only within each foil and did not overpass the foil surfaces on which the GNSs were deposited. The orientation feature of each $\mathrm{Cu}$ foil infers that the Cube oriented grains had the absolute privilege to survive and grow by consuming the other orientation grains until they joined each other.
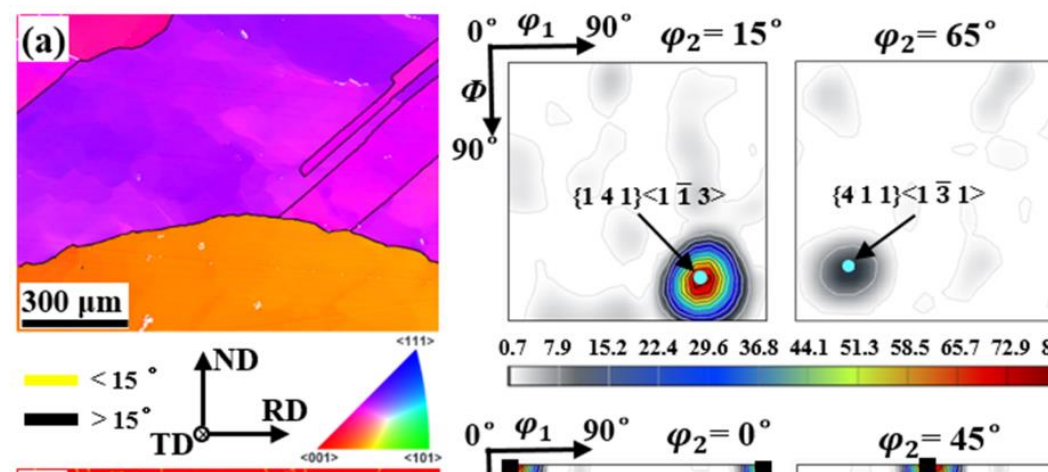

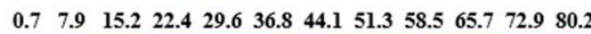

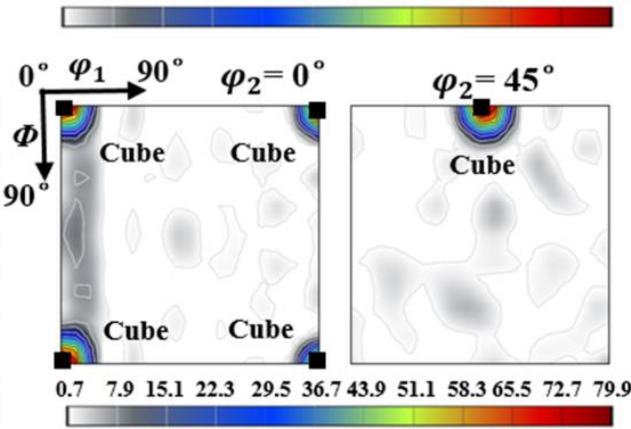

Fig. 3. EBSD RD-IPF micrographs and representative ODF $\varphi_{2}$ sections from neutron diffraction of as-fully-sintered (a) pure $\mathrm{Cu}\left(\varphi_{2}=15^{\circ}\right.$ and $\left.65^{\circ}\right)$ and (b) $\mathrm{Cu} / \mathrm{GNS}$ composite $\left(\varphi_{2}=0^{\circ}\right.$ and $\left.45^{\circ}\right)$.

\subsection{Microstructure and orientation evolution of pure $\mathrm{Cu}$ and $\mathrm{Cu} / \mathrm{GNS}$ during heating}

To investigate the microstructure and texture evolution features of the $\mathrm{Cu} / \mathrm{GNS}$ composite samples with respect to the pure $\mathrm{Cu}$ samples during the sintering process, the as-cold-rolled $\mathrm{Cu}$ and $\mathrm{Cu} / \mathrm{GNS}$ 
samples were heated to 5 different temperatures $\left(150^{\circ} \mathrm{C}, 170{ }^{\circ} \mathrm{C}, 230^{\circ} \mathrm{C}, 450{ }^{\circ} \mathrm{C}\right.$ and $\left.700{ }^{\circ} \mathrm{C}\right)$ and then quenched in compressed argon flow to preserve the as-heated microstructure and texture. Fig. 4 shows the EBSD Kernel Average Misorientation (KAM) micrographs of single-foil $\mathrm{Cu}$ of the pure $\mathrm{Cu}$ and $\mathrm{Cu} / \mathrm{GNS}$ samples heated to $150^{\circ} \mathrm{C}$ and $170^{\circ} \mathrm{C}$ (Fig. $4 \mathrm{~b}$ and Fig. $4 \mathrm{c}$ ), respectively, and the EBSD texture component micrographs of the single-foil $\mathrm{Cu}$ of the pure $\mathrm{Cu}$ and $\mathrm{Cu} / \mathrm{GNS}$ samples heated to $230^{\circ} \mathrm{C}$, $450^{\circ} \mathrm{C}$ and $700^{\circ} \mathrm{C}$ (Fig. $4 \mathrm{~d}, 4 \mathrm{e}$ and $4 \mathrm{f}$ ), respectively. For reference, the KAM micrograph of the initial cold-rolled $\mathrm{Cu}$ is also displayed (Fig. 4a). It is seen from Fig. 4b that with the increase of the heating temperature from $150^{\circ} \mathrm{C}$ to $170^{\circ} \mathrm{C}$ the microstructures are still in band form, however, at $150^{\circ} \mathrm{C}$ in both the pure $\mathrm{Cu}$ and the $\mathrm{Cu} / \mathrm{GNS}$ sample, the density of the disorientation that represents the density of Geometrical Necessary Dislocations (GNDs) decreased in certain regions in the bands, as indicated with the white arrows in the figures, indicating the occurrence of recovery or the early recrystallization nucleation. When the heating temperature was increased to $170^{\circ} \mathrm{C}$, small equiaxed and distortion-free grains started to appear in the two samples, as indicated with the yellow arrows in the micrographs, indicating the onset of recrystallization. When the samples were further heated to $230^{\circ} \mathrm{C}$, recrystallization continued. In the $\mathrm{Cu} / \mathrm{GNS}$ sample, the initially banded microstructure was totally replaced by recrystallized grains, whereas in the pure $\mathrm{Cu}$ sample, the recrystallization was still in progress with the microstructure composed of recrystallized grains and deformed bands. The orientations of the recrystallized grains in the two cases are close to those of the cold-rolled texture components, as evidenced by the consistent colors of the texture components in Fig. $4 \mathrm{~d}$. The Cube oriented grains did not show any preference in growth. When the heating temperature was elevated to $450^{\circ} \mathrm{C}$, abnormal grain growth occurred in the $\mathrm{Cu} / \mathrm{GNS}$ sample (Fig. 4e $\mathrm{e}_{2}$ ). The Cube grains demonstrate strong growth preference. However, in the pure $\mathrm{Cu}$ sample, the recrystallization fully terminated and some recrystallized grains started to grow. Compared with the $\mathrm{Cu} / \mathrm{GNS}$ sample, the grain growth did not occur preferentially to the Cube oriented grains. When the samples were further heated to $700^{\circ} \mathrm{C}$, although abnormal grain growth occurred in the two samples, almost all the $\mathrm{Cu} / \mathrm{GNS}$ sample is occupied by the Cube grains, whereas the pure $\mathrm{Cu}$ sample is mainly occupied by the Goss oriented grains in the observed area. These results infer that the GNSs deposited on the cold-rolled $\mathrm{Cu}$ foils indeed promoted the growth of the Cube oriented grains. 


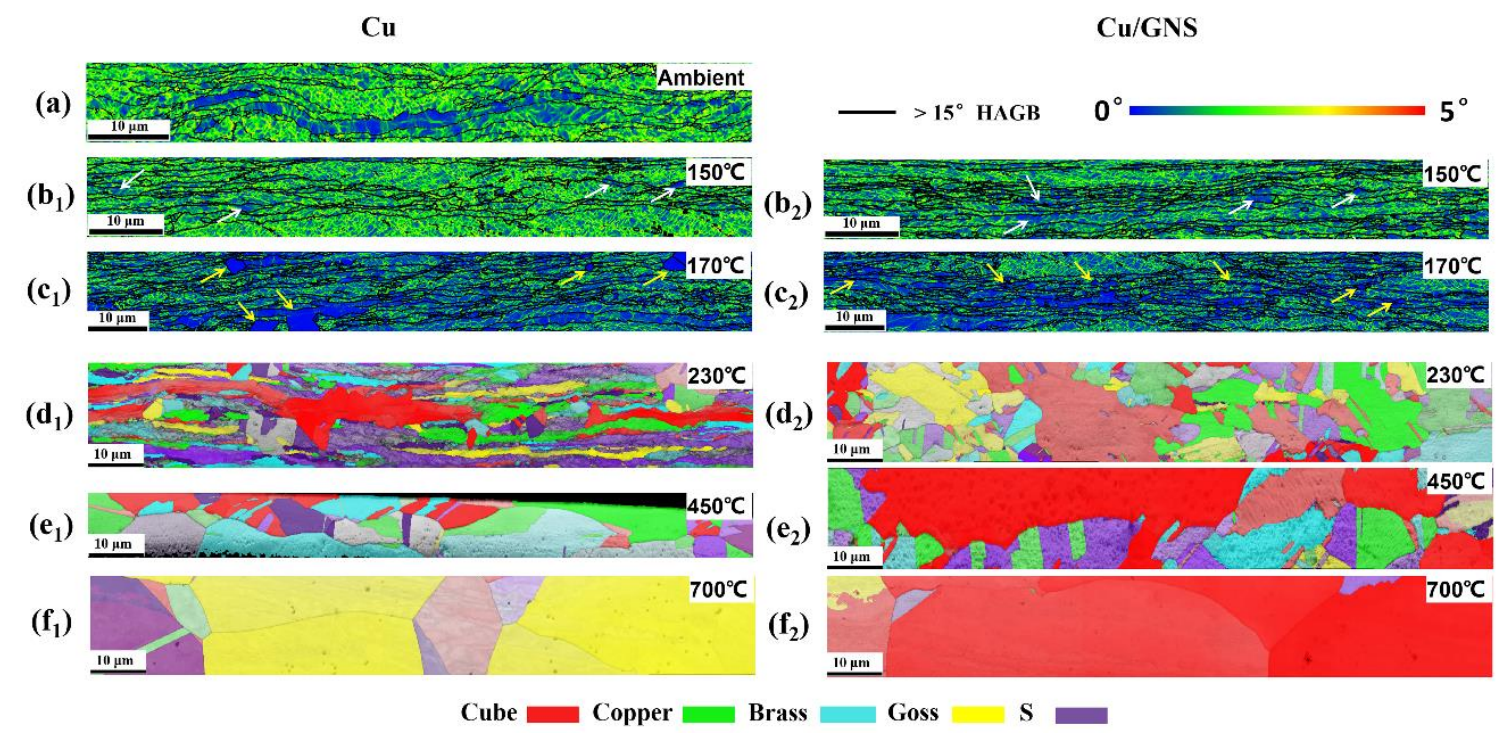

Fig. 4. Kernel Average Misorientation (KAM) micrographs of (a) $\mathrm{Cu}$ cold-rolled at ambient temperature and of $\mathrm{Cu}$ in pure $\mathrm{Cu}$ and $\mathrm{Cu} / \mathrm{GNS}$ samples heated to (b) $150{ }^{\circ} \mathrm{C}$ and (c) $170{ }^{\circ} \mathrm{C}$, respectively. EBSD texture component micrographs of $\mathrm{Cu}$ in pure $\mathrm{Cu}$ and $\mathrm{Cu} / \mathrm{GNS}$ heated to (d) $230^{\circ} \mathrm{C}$, (e) $450{ }^{\circ} \mathrm{C}$ and (f) $700{ }^{\circ} \mathrm{C}$, respectively.

The texture evolution during the recrystallization and grain growth processes was also quantitatively examined in a large sample volume by neutron diffraction. Fig. 5 shows the ODF sections of the pure $\mathrm{Cu}$ and the $\mathrm{Cu} / \mathrm{GNS}$ composite sample heated to different temperatures $\left(150{ }^{\circ} \mathrm{C}, 170{ }^{\circ} \mathrm{C}, 230{ }^{\circ} \mathrm{C}\right.$ and $450{ }^{\circ} \mathrm{C}$ ) calculated from the neutron diffraction results measured from the whole sample volume. It is seen from Fig. $5 \mathrm{a}_{1}, 5 \mathrm{a}_{2}, 5 \mathrm{~b}_{1}$ and $5 \mathrm{~b}_{2}$ that both the pure $\mathrm{Cu}$ and the $\mathrm{Cu} / \mathrm{GNS}$ samples still possess similar texture components but with different intensities with respect to those of the cold-rolled $\mathrm{Cu}$. The spread of the Brass component along the $\alpha$ skeleton line toward the Goss orientation in the cold-rolled microstructure disappeared and the Cube component became strengthened, especially in the $\mathrm{Cu} / \mathrm{GNS}$ sample. When the heating temperature was increased to $230{ }^{\circ} \mathrm{C}$, the texture evolutions in the two samples were quite different. In the $\mathrm{Cu} / \mathrm{GNS}$ sample, the non-Cube orientations greatly weakened, whereas the Cube orientation strengthened. However, in the pure $\mathrm{Cu}$ sample, the Cube component slightly weakened, whereas the Copper component strengthened. When the heating temperature increased to $450^{\circ} \mathrm{C}$, in the $\mathrm{Cu} / \mathrm{GNS}$ sample, the Cube component continued to develop and the other orientations largely disappeared, whereas, in the pure $\mathrm{Cu}$ sample, the existing orientations all continued to decrease their intensities. These results indicate that the GNSs indeed provided a unique driving force for the growth of the Cube grains during the grain growth process. 

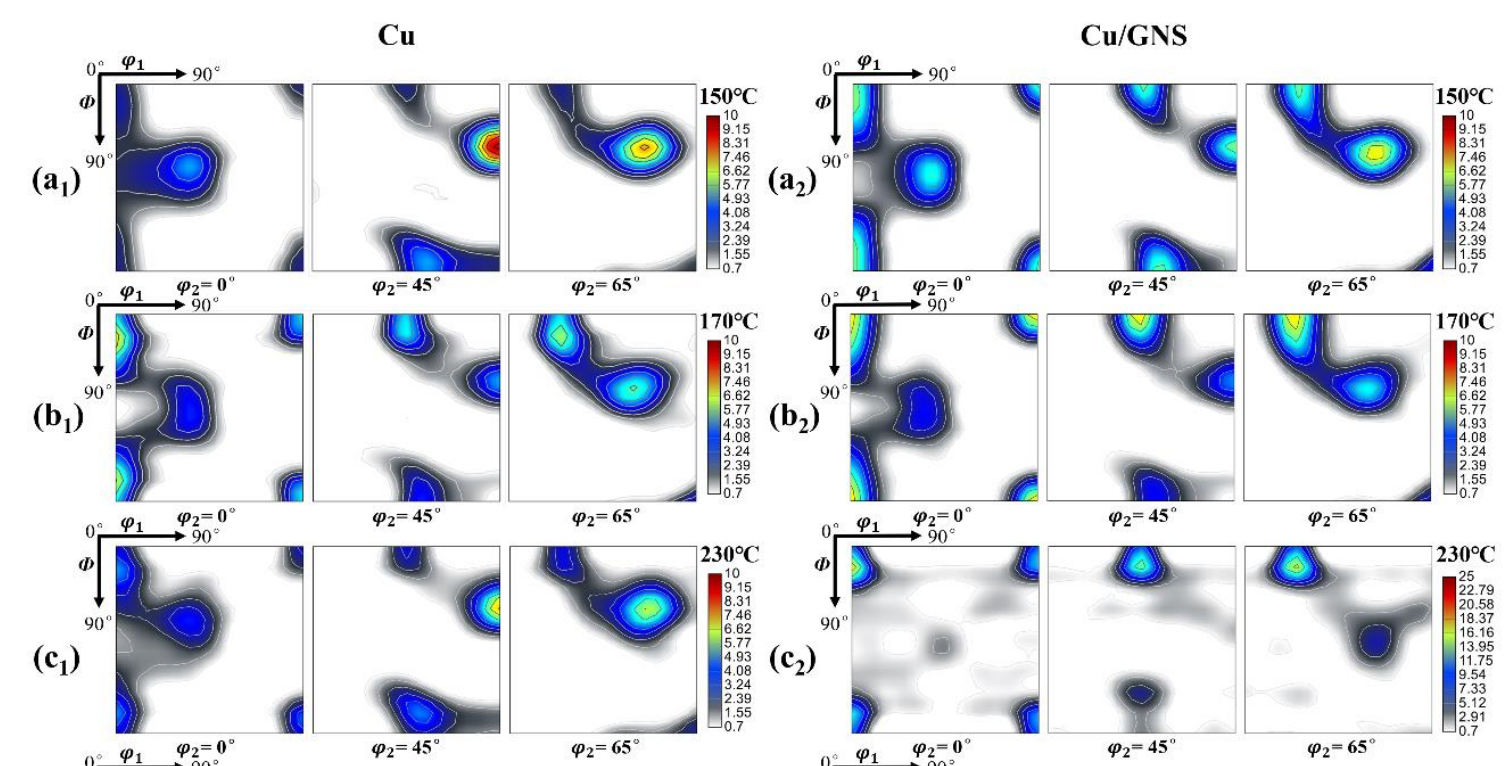

$\left(\mathbf{d}_{1}\right)$
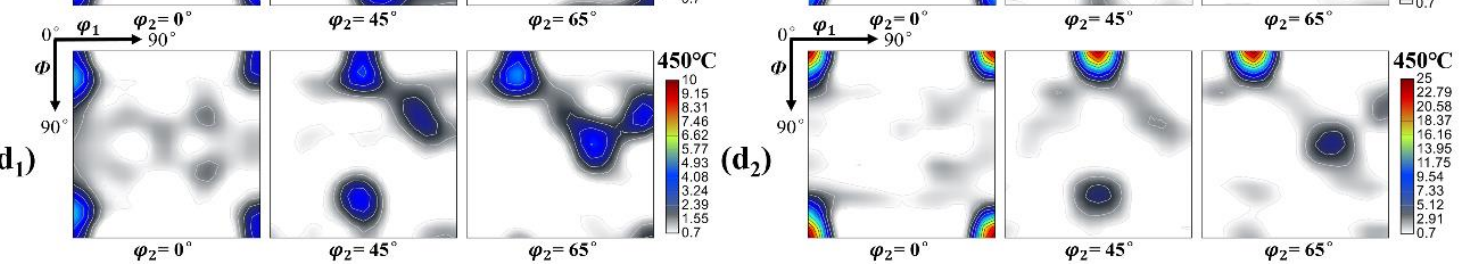

Fig. 5. Neutron diffraction ODF $\varphi_{2}=0^{\circ} ; 45^{\circ} ; 65^{\circ}$ sections of pure $\mathrm{Cu}$ samples heated to $\left(\mathbf{a}_{1}\right) 150^{\circ} \mathrm{C} ;\left(\mathbf{b}_{1}\right) 170^{\circ} \mathrm{C} ;\left(\mathbf{c}_{1}\right)$ $230^{\circ} \mathrm{C} ;\left(\mathbf{d}_{1}\right) 450^{\circ} \mathrm{C}$ and of $\mathrm{Cu} / \mathrm{GNS}$ samples heated to $\left(\mathbf{a}_{2}\right) 150^{\circ} \mathrm{C} ;\left(\mathbf{b}_{2}\right) 170^{\circ} \mathrm{C} ;\left(\mathbf{c}_{2}\right) 230^{\circ} \mathrm{C} ;\left(\mathbf{d}_{2}\right) 450^{\circ} \mathrm{C}$.

\subsection{Thermal expansion of $\mathrm{Cu}$ and $\mathrm{Cu} / \mathrm{GNS}$ during heating and relative lattice strains induced by GNS}

As the promotion of the GNSs to the Cube grain growth occurred during the heating process, the incompatible thermal expansion behavior between the two materials should result in thermal constraints to the softer $\mathrm{Cu}$. This may lie behind the abnormal grain growth. Thus, in order to clarify the constraints, the evolution of the lattice strains of the $\mathrm{Cu}$ in the two kinds of samples during the heating process was investigated by the $4 \mathrm{D}$ in-situ synchrotron radiation technique $(3 \mathrm{D}$ space $+1 \mathrm{D}$ time). Fig. 6 displays the Debye-Scherrer pattern of the initial cold-rolled $\mathrm{Cu}$ sample and the integrated 1D $\mathrm{Cu}$ diffraction patterns from the pure $\mathrm{Cu}$ and the $\mathrm{Cu} / \mathrm{GNS}$ composite sample in the $2 \theta$ range from $3^{\circ}$ to $5.5^{\circ}$ measured during heating, where the $\{111\}_{\mathrm{Cu}}$, the $\{200\}_{\mathrm{Cu}}$ and the $\{220\}_{\mathrm{Cu}}$ reflection peaks were detected. It is seen from the two integrated peak figures that with the increase of the temperature all the detected peaks shifted toward the lower $2 \theta$ angle side, as indicated by the black arrows in the figures. According to the Bragg's law, such a shift of $2 \theta$ corresponds to the increase of the interplanar spacing (d-spacing) of these planes with the temperature. Thus, thermal expansion of $\mathrm{Cu}$ occurred during the heating process. 

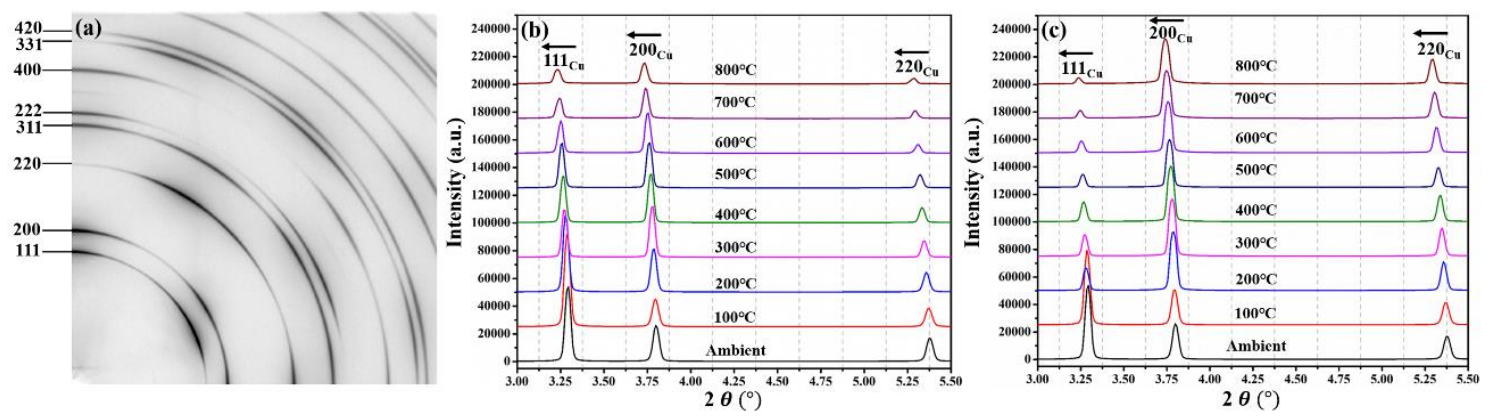

Fig. 6. HEXRD patterns for (a) the initial cold-rolled $\mathrm{Cu}$ sample obtained using a 2D detector and as-integrated 1D diffraction patterns of (b) pure $\mathrm{Cu}$ and (c) $\mathrm{Cu} / \mathrm{GNS}$ at temperatures from ambient to $800^{\circ} \mathrm{C}$. The intensity profile of each pattern was obtained by integrating the intensity of corresponding 2D Debye-Scherrer rings in the full azimuth angle range.

To analyze the characteristic lattice strain states of the $\mathrm{Cu}$ foils in the $\mathrm{Cu} / \mathrm{GNS}$ sample with respect to those of the pure $\mathrm{Cu}$, the in-plane (parallel to the foil plane) and out-of-plane (perpendicular to the foil plane) thermal expansion characteristics were further analyzed for the two kinds of samples. Under the geometrical arrangement of the synchrotron diffraction measurements (Fig. 1), the samples were fixed during the whole heating process, and the incident beam was set to be parallel to the TD of each $\mathrm{Cu}$ foil in the pure $\mathrm{Cu}$ and $\mathrm{Cu} / \mathrm{GNS}$ samples. Thus, the change of the $\mathrm{d}$-spacing of the lattice planes perpendicular to the RD was used to analyze the in-plane strain, and the change of the d-spacing of the lattice planes perpendicular to the ND the out-of-plane strain. Fig. 7a and 7b shows the RD and ND $\mathrm{d}_{h k l}$ of the $\{111\}_{\mathrm{Cu}}$ and $\{200\}_{\mathrm{Cu}}$ planes of the $\mathrm{Cu}$ foils in the pure $\mathrm{Cu}$ and in the $\mathrm{Cu} / \mathrm{GNS}$ samples. It is seen that, in general, the $\mathrm{d}_{h k l}$ of each lattice plane increases linearly with the temperature. The difference in $\mathrm{d}_{h k l}$ between the RD and ND is due to the 2D feature of the thin $\mathrm{Cu}$ foils. 

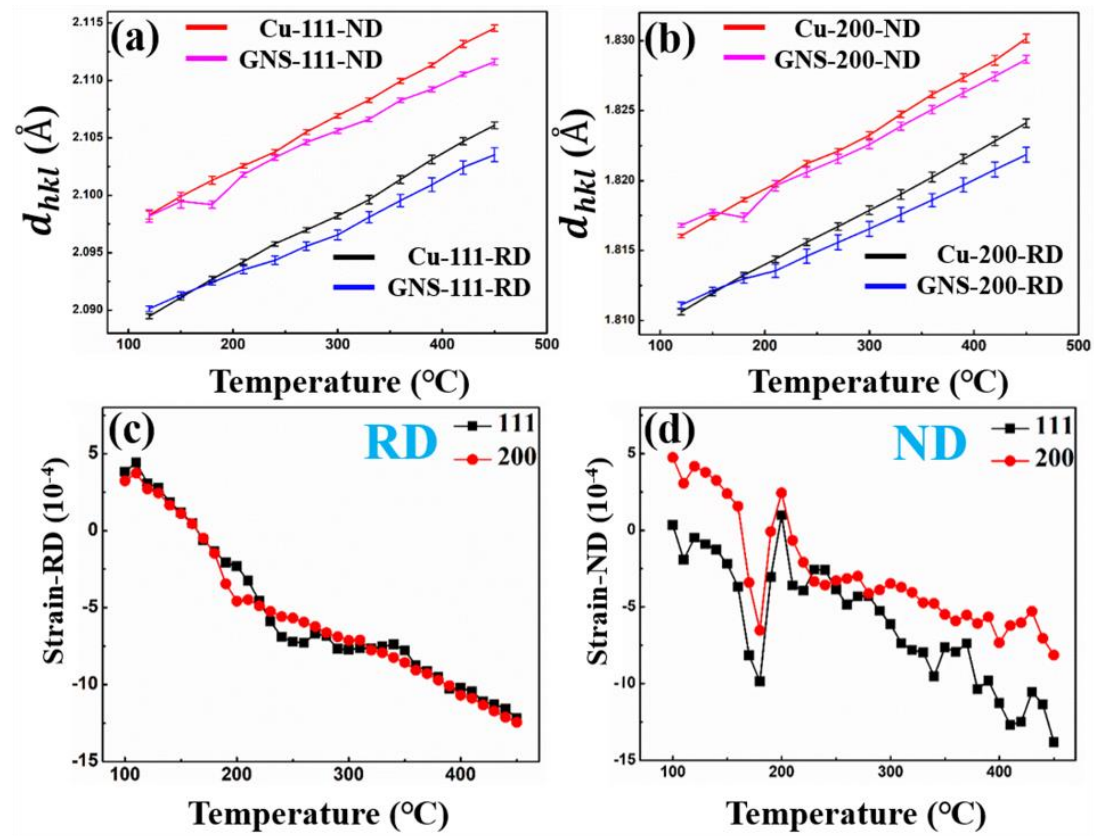

Fig. 7. Comparison of $\mathrm{d}_{h k l}$ of (a) $\{111\} \mathrm{Cu}$, (b) $\{200\}_{\mathrm{Cu}}$ of the two samples and relative lattice strains of $\mathrm{Cu}$ in $\mathrm{Cu} / \mathrm{GNS}$ with respect to that of $\mathrm{Cu}$ in pure $\mathrm{Cu}$ (c) in $\mathrm{RD}$ (in-plane) and (d) in ND (out-of-plane).

However, when we compare the slopes of the $\mathrm{d}_{h k l}$ curves of the Cu/GNS sample with those of the pure $\mathrm{Cu}$ sample in the same direction, we can find that with the increase of the temperature, $d_{h k l_{C u}(T)}$ increases more rapidly than $d_{h k l_{G N S / C u}(T)}$, especially at higher temperatures. This indicates that the deposited GNSs on the surfaces of the $\mathrm{Cu}$ foils indeed imposed constraints to the thermal expansion of the $\mathrm{Cu}$ foils. To figure out the constraints from the GNSs, we calculated the relative lattice strain (Belonging to Type I, macro strain [39], giving rise to a shift of the diffraction peaks) of the $\mathrm{Cu}$ in the $\mathrm{Cu} / \mathrm{GNS}$ sample with respect to that of the $\mathrm{Cu}$ in the pure $\mathrm{Cu}$ sample in the consistent direction at each temperature as expressed by Eq. (1):

$$
\varepsilon=\frac{d_{h k l_{G N S / C u}(T)}-d_{h k l_{C u}(T)}}{d_{h k l_{C u}(T)}},
$$

where $d_{h k l_{G N S / C u}(T)}$ and $d_{h k l_{C u}(T)}$ are the $\mathrm{d}_{h k l}$ of $\mathrm{Cu}$ in the $\mathrm{Cu} / \mathrm{GNS}$ and in the pure $\mathrm{Cu}$ sample at temperature $T$. The results are displayed in Fig 7c and 7d. It is seen from Fig. 7c that the GNSs induced a compressive strain in the plane parallel to the $\mathrm{Cu}$ foil plane (in-plane strain). This in-plane strain possesses bi-axial character, as the $\mathrm{Cu}$ layers in the sample are in thin foil shape, especially when the recrystallization was complete and the banded microstructure was replaced by the equiaxed recrystallized grains. Interestingly, the $\{200\}_{\mathrm{Cu}}$ and $\{111\}_{\mathrm{Cu}}$ strains were consistent during the whole heating process, inferring that the $\mathrm{Cu}$ foils possess an isostrain feature. Similarly, in the ND (Fig. 7d), 
the GNSs also introduced a compressive strain in the direction normal to the foil plane (out-of-plane strain). Although the value of the $\{111\} \mathrm{Cu}$ strain is not exactly the same as that of the $\{200\} \mathrm{Cu}$ strain at each temperature, the magnitudes of the two strains are very close. In the two cases, the absolute values of the strains increased linearly with the temperature, demonstrating an elastic condition.

Further examination of the diffraction patterns revealed that different levels of peak broadening occurred to the $\{200\}_{\mathrm{Cu}}$ peaks in the two kinds of samples. Because a wide diffraction peak corresponds to a spread of d-spacing of the reflective lattice plane, the broadening of the peak infers a large variation of the lattice strain (Type II and III [39], mesoscopic and micro strain, manifested as broadening of the diffraction peaks), from a negative strain to a positive strain, if the peak is symmetric, which is the case in the present study. Thus, the Full Width at Half Maximum (FWHM) [41, 42] of the representive $\{200\}_{\mathrm{Cu}}$ peaks of the pure $\mathrm{Cu}$ and the $\mathrm{Cu} / \mathrm{GNS}$ in the respective $\mathrm{RD}$ and ND was extracted and displayed in Fig. 8a and b, respectively. As the FWHM are very sensitive to crystal defects, especially dislocations (the Type III strain [39]) that possess both lattice tension and compression around the dislocation lines, the progressive decrease and then a rapid decrease of the FWHM values below $210^{\circ} \mathrm{C}$ for the pure $\mathrm{Cu}$ sample and below $170^{\circ} \mathrm{C}$ for the $\mathrm{Cu} / \mathrm{GNS}$ sample are related to the progressive and then rapid annihilation of dislocations during the recovery and recrystallization processes. After these temperatures, the FWHM values of the two kinds of samples stay relatively constant (Fig. 8a and b). However, the RD-FWHM of the $\mathrm{Cu} / \mathrm{GNS}$ sample behaves very abnormally, as shown in Fig. 8b. Instead of decrease, a drastic increase appeared although recrystallization had already completed and the dislocations had been largely eliminated (corresponding to the disappearance of the Type III strain [39]). Such a high level RD-FWHM infers that the compressive biaxial strain in the $\mathrm{Cu}$ foil plane is not constant everywhere. With respect to the average strain (corresponding to the diffraction peak), some parts of the foil were compressed and the other parts tensed. This result infers that the GNSs indeed imposed complicated constraints to the $\mathrm{Cu}$ foil (the Type II strain [39]). The multiple strain states of $\mathrm{Cu}$ will be analyzed in detail in the next part. 

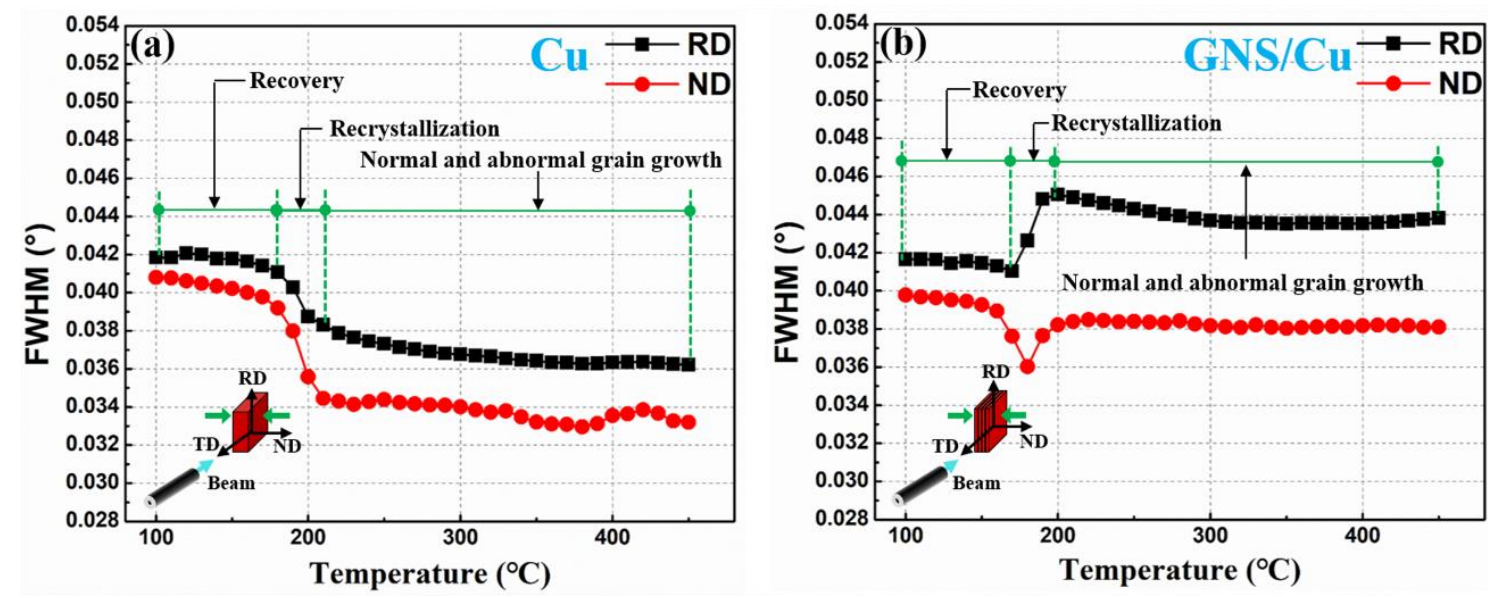

Fig.8. FWHM of $\{200\}_{\text {Cu }}$ peaks for (a) pure $\mathrm{Cu}$ and (b) $\mathrm{Cu} / \mathrm{GNS}$ in RD and ND on heating.

\section{Discussion}

\subsection{Incompatible thermal expansion induced elastic strain states in $\mathrm{Cu}$ foil}

The above results demonstrated that the GNSs deposited on the $\mathrm{Cu}$ surfaces imposed obvious constraints to the $\mathrm{Cu}$ foils during the heating process that significantly affected the growth of the recrystallized grains and modified the texture of the $\mathrm{Cu}$ foils. As the constraints occurred during the heating process and thermal expansion of the two materials is inevitable, the different thermal expansion behavior of the two should be at the origin. Fig.9 displays the TECs of $\mathrm{Cu}$, graphite and graphene. The difference between graphite and graphene lies in the number of the two-dimensional hexagonally structured carbon layers. For the multi-layered graphene ( $<15$ layers) used in the present study, the expansion behavior shows different in-plane and out-of-plane features. The in-plane expansion behavior should be between that of graphene and graphite (> 10 layers [43]), i.e., with negative TEC values (Fig. 9), and the out-of-plane behavior should be close to that of graphite, i.e., with large positive TEC values even higher than those of $\mathrm{Cu}$. For $\mathrm{Cu}$, the expansion is isotropic with large positive TEC values. Thus, at elevated temperatures, the $\mathrm{Cu}$ of the $\mathrm{Cu} / \mathrm{GNS}$ composite tended to expand in the planes parallel to the foil plane (in-plane), whereas the GNSs adhered on the $\mathrm{Cu}$ tended to shrink. The negative thermal expansion of the GNSs exerted a biaxial in-plain compressive constraint to the expansion of the $\mathrm{Cu}$ foil. However, in the out-of-plain direction, both the GNSs and the $\mathrm{Cu}$ foils expanded during heating. It should be noted that the samples were fixed by a holding frame in this direction during the heating process. Thus, with higher hardness and larger TEC, the GNSs exerted a uniaxial compressive constraint to the $\mathrm{Cu}$ foils in the direction perpendicular to the 
foil plane. Finally, a biaxial strain parallel to the $\mathrm{Cu}$ foil plane and a uniaxial compressive strain perpendicular to the $\mathrm{Cu}$ foil plane were produced in the $\mathrm{Cu}$ foils by the deposited GNSs on the $\mathrm{Cu}$ foil surfaces.

As the GNSs used in the present composite are very thin $(1 \sim 5 \mathrm{~nm}$ in thickness $)$ with respect to the $\mathrm{Cu}$ foils (30 $\mu \mathrm{m}$ thickness), the biaxial constraint should be mainly situated in the surface layers of each $\mathrm{Cu}$ foil. With the increase of the depth to the central layer, this constraint decreases and the uniaxial compressive constraint in the foil normal direction (ND) becomes dominant. This means that the central layer experienced a tension in the foil plane from the uniaxial compression other than the compression from the in-plane shrinkage of the GNSs. Thus, the strain in RD changed from a compression in the surface layer to a tension in the central layer and resulted in a large variation of $d_{h k l}$ and in turn the increased RD-FWHM (Fig. 8b). Thus, during the heating process, each Cu foil was in a composite strain state, i.e., the two surface layers were in biaxial compressive isostrain state in the foil plane and the central layer was in the uniaxial compression state in the direction normal to the foil plane. Clearly, it should be this complicated strain state that sustained the growth of the Cube grains in the $\mathrm{Cu} / \mathrm{GNS}$ composite. The reason for this is certainly related to the interplay between the strain state and the crystal orientation related elastic feature of $\mathrm{Cu}$. Thus, the orientation-resolved elastic strain energy as the result of the interplay was further investigated.

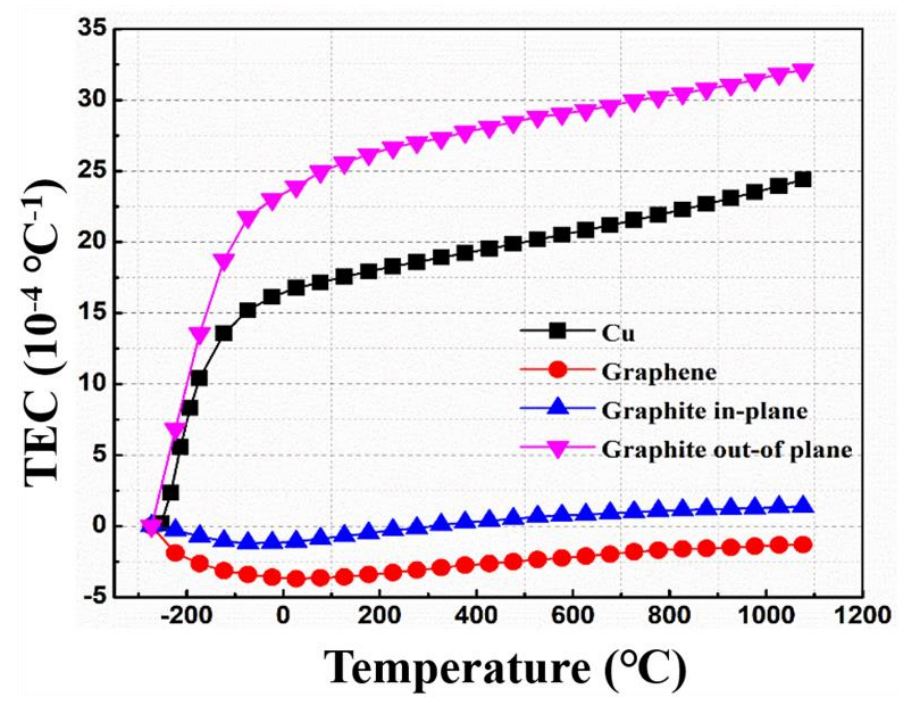

Fig. 9. Variations of thermal expansion coefficients (TECs) of $\mathrm{Cu}$ [44] and graphene [45] with temperature, and variations of in-plane and out-of-plane TECs of graphite [45] with temperature.

4.2 Orientation dependent elastic strain energy density of strained crystals 
With the above analyzed strain state of the $\mathrm{Cu}$ foils, the stress state can be further derived and the elastic strain energy density can be calculated. In the theory of elasticity, if a crystal is elastically strained, the stress tensor $\sigma_{i j}$ is related to the strain tensor $\varepsilon_{k l}$ through the stiffness constant tensor $C_{i j k l}$, as expressed in the following equation in Nye's notation [46]:

$$
\sigma_{i j}=C_{i j k l} \cdot \varepsilon_{k l},
$$

where the subscripts $i, j, k$ and $l$ take the integer values 1,2 and 3. The matrix expression of Eq. (2) is given as Eq. (A1) in Appendix. A2. Due to the cubic crystal symmetry of $\mathrm{Cu}$, the independent elastic constants of $\mathrm{Cu}$ in the crystal coordinate system are $\mathrm{C}_{11}, \mathrm{C}_{12}$ and $\mathrm{C}_{44}$ with the corresponding values of 169, 122 and 75.3 GPa [7, 47], respectively. Eq. (2) for cubic crystals is given in Eq. (A2) in Appendix. A2. As the elastic strains were determined in the sample coordinate system (RD-TD-ND), the stress and strain are further related by

$$
\sigma_{i j}^{\prime}=C^{\prime}{ }_{i j k l} \cdot \varepsilon^{\prime}{ }_{k l}
$$

in the sample coordinate system, where $C^{\prime}{ }_{i j k l}=A_{i m} A_{j n} A_{k o} A_{l p} C_{m n o p}(i, j, k, l, m, n, o$ and $p$ all take integral values from 1 to 3$)$ and $A_{r t}(r=i, j, k, l$ and $t=m, n, o, p)$ are direction cosine of the basis vectors of the crystal coordinate system with respect to the basis vectors of the sample coordinate system. Thus, the elastic strain energy density can be calculated as follows:

$$
W=\frac{1}{2} \sigma_{i j}^{\prime} \cdot \varepsilon^{\prime}{ }_{i j}
$$

\subsubsection{Biaxial strain condition}

In the present sample coordinate system, axes 1 and 2 stand for the respective RD and TD that define the plane parallel to the $\mathrm{Cu}$ foil plane and axis 3 stands for the ND normal to the foil plane. For the biaxial strain condition, the strain in the planes parallel to the foil plane is

$$
\varepsilon_{11}^{\prime}=\varepsilon_{22}^{\prime}=\varepsilon^{\prime}
$$

The stress components that are not in the plane of the $\mathrm{Cu}$ foil can be considered to be zero, i.e.,

$$
\sigma_{23}^{\prime}=\sigma_{13}^{\prime}=\sigma_{33}^{\prime}=0 .
$$

As the GNSs were firmly embedded in the $\mathrm{Cu}$ foils,

$$
\sigma_{12}^{\prime}=0 .
$$

Under these boundary conditions and with the cubic symmetry of $\mathrm{Cu}$, the following equations can be obtained: 


$$
\begin{aligned}
& \sigma_{11}^{\prime}=C_{1111}^{\prime} \varepsilon_{11}^{\prime}+C_{1122}^{\prime} \varepsilon_{22}^{\prime}+C_{1133}^{\prime} \varepsilon_{33}^{\prime} \\
& \sigma_{22}^{\prime}=C_{2211}^{\prime} \varepsilon_{11}^{\prime}+C_{2222}^{\prime} \varepsilon_{22}^{\prime}+C_{2233}^{\prime} \varepsilon^{\prime}{ }_{33} \\
& \sigma_{12}^{\prime}=C_{1211}^{\prime} \varepsilon_{11}^{\prime}+C_{1222}^{\prime} \varepsilon_{22}^{\prime}+C_{1233}^{\prime} \varepsilon_{33}^{\prime} .
\end{aligned}
$$

Thus, the biaxial moduli of plane $(h k l)$ in the two in-plane directions ( 1 or RD and 2 or TD) is given by:

$$
\begin{aligned}
& M_{1}=\frac{\sigma_{11}}{\varepsilon}=C_{1111}^{\prime}+C_{1122}^{\prime}-\frac{1}{C_{3333}}\left(C_{1133}^{\prime}{ }^{2}+C_{1133}^{\prime} C_{2233}^{\prime}\right) \\
& M_{2}=\frac{\sigma_{22}}{\varepsilon}=C_{2211}^{\prime}+C_{2222}^{\prime}-\frac{1}{C_{3333}}\left(C_{2233}^{\prime}{ }^{2}+C_{1133}^{\prime} C_{2233}^{\prime}\right) .
\end{aligned}
$$

Hence, the linear mean value of the biaxial modulus for a plane $(h k l)$ subjected to biaxial strain, $\bar{M}_{h k l}$, is:

$$
\bar{M}_{h k l}=\frac{1}{2}\left(M_{1}+M_{2}\right)
$$

It should be noted that an equivalent way to obtain the coordinate transformation $A_{r t}$ between the orthonormal sample coordinate system and the orthonormal crystal coordinate system can be made by representing the relation between the two coordinate systems with a set of triple rotations, i.e., Euler angles $\left(\varphi_{1}, \Phi, \varphi_{2}\right)$, in Bunge notation [40,48], and expressing it in the rotation matrix, as follows

$$
A_{r t}=R\left(\varphi_{1}\right) R(\Phi) R\left(\varphi_{2}\right)=\left[\begin{array}{ccc}
u_{1} & v_{1} & w_{1} \\
u_{2} & v_{2} & w_{2} \\
h & k & l
\end{array}\right] .
$$

In such a matrix, all the row elements are related to the foil plane. The $(h k l)$ represents the crystalline plane parallel to the foil plane or normal to axis 3 (the ND), the $\left[\begin{array}{lll}u_{1} & v_{1} & w_{1}\end{array}\right]$ and $\left[\begin{array}{lll}u_{2} & v_{2} & w_{2}\end{array}\right]$ are two orthogonal in-plane unit vectors parallel to the respective axis 1 and axis 2, i.e., the RD and the TD. Once the matrix is constructed, the crystalline plane that is parallel to the foil plane and the directions parallel to the RD and the TD are known. Thus, in the biaxial strain condition, the elastic strain energy density can be calculated with the following equation:

$$
W=\frac{1}{2} \bar{M}_{h k l} \cdot \varepsilon^{\prime}(h k l){ }^{2} .
$$

\subsubsection{Uniaxial compression condition}

Under this condition, the crystal is only subjected to a uniaxial stress in axis 3 (the ND), i.e., $\sigma_{33}^{\prime}$ and all other normal stress components and all shear stress components are equal to zero, i.e., 


$$
\sigma_{11}^{\prime}=\sigma_{22}^{\prime}=\sigma_{23}^{\prime}=\sigma_{13}^{\prime}=\sigma_{12}^{\prime}=0 \text {. }
$$

Utilizing Eq. (13) as boundary conditions and with cubic crystal symmetry, the following stress and strain relations can be obtained:

$$
\begin{aligned}
& \sigma_{11}^{\prime}=0=C_{1111}^{\prime} \varepsilon_{11}^{\prime}+C_{1122}^{\prime} \varepsilon_{22}^{\prime}+C_{1133}^{\prime} \varepsilon_{33}^{\prime} \\
& \sigma_{22}^{\prime}=0=C_{2211}^{\prime} \varepsilon_{11}^{\prime}+C_{2222}^{\prime} \varepsilon_{22}^{\prime}+C_{2233}^{\prime} \varepsilon^{\prime}{ }_{33} \\
& \sigma_{33}^{\prime}=C^{\prime}{ }_{3311} \varepsilon^{\prime}{ }_{11}+C^{\prime}{ }_{3322} \varepsilon_{22}^{\prime}+C^{\prime}{ }_{3333} \varepsilon^{\prime}{ }_{33} .
\end{aligned}
$$

Thus, the elastic modulus in the compressive stress direction can be deduced and is as follows:

$$
E_{33}^{\prime}=\frac{\sigma_{33}}{\varepsilon_{33}}=\left(C^{\prime}{ }_{1111} C_{2233}^{\prime}{ }^{2}+C_{2222}^{\prime} C_{1133}^{\prime}{ }^{2}-2 C^{\prime}{ }_{1122} C_{1133}^{\prime} C_{2233}^{\prime}\right) /\left(C_{1122}^{\prime}{ }^{2}-C_{1111}^{\prime} C_{2222}^{\prime}\right)+C_{3333}^{\prime} \text {. }
$$

Then, the strain energy density associated with the uniaxial compression is:

$$
W=\frac{1}{2} E_{33}^{\prime} \cdot \varepsilon^{\prime}{ }_{33}^{2}
$$

\subsubsection{Simulated elastic modulus for the two strain conditions}

The above analyses show that both the biaxial elastic strain energy and the uniaxial compressive elastic strain energy are crystal orientation related. The former is proportional to the biaxial modulus $\bar{M}_{h k l}$ and the latter to the Young's modulus in the direction normal to the foil plane or the $(h k l)$ plane, $E^{\prime}{ }_{33}$. For the grains in the surface layers of the $\mathrm{Cu}$ foils in the $\mathrm{Cu} / \mathrm{GNS}$ sample, they demonstrated a biaxial isostrain feature (Fig. 7c), meaning that for differently oriented grain the elastic strains induced by the GNSs are the same. Thus, the strain energy is solely determined by $\bar{M}_{h k l}$. As Cu is elastically anisotropic, if differently oriented grains were subjected to the same biaxial strain, the strain energies of the grains should be very different. Thus, we simulated the $\bar{M}_{h k l}$ of all possibly oriented Cu crystals and the orientation-resolved $\bar{M}_{h k l}$ represented in the orientation space is displayed in Fig. 10. It is seen that the $\bar{M}_{h k l}$ is indeed very anisotropic, varying from $114.18 \mathrm{GPa}$ to $261.26 \mathrm{GPa}$. The lowest $\bar{M}_{h k l}(114.86 \mathrm{GPa})$ is associated with the grains having their $\{002\} \mathrm{Cu}$ parallel to the foil plane and the highest $\bar{M}_{h k l}(261.26 \mathrm{GPa})$ with those possessing their $\{111\}$ Cu parallel to the foil plane. Thus, in the biaxial isostrain state, the grains with the $\{002\} \mathrm{Cu}$ parallel to the foil plane possess the lowest elastic strain energy and are energetically advantageous to grow. Consequently, during the heating process when grain growth occurred, the growth of the Cube oriented grains was stimulated, as their growth can effectively minimize the elastic strain energy and hence the total energy of the system. 


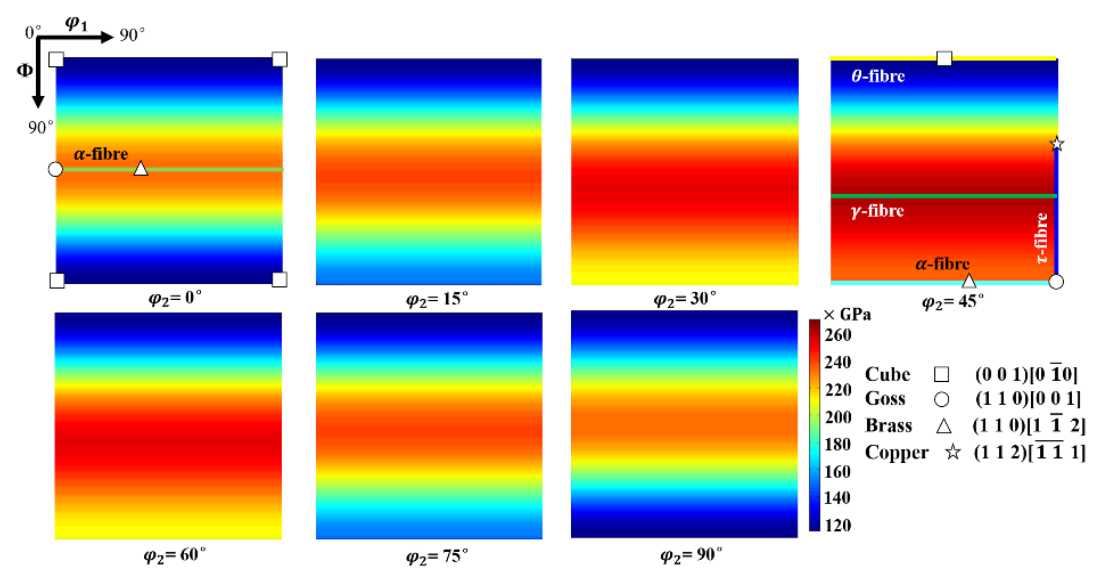

Fig. 10. $\varphi_{2}=0^{\circ}$ to $90^{\circ}$ sections of mean biaxial modulus $\bar{M}_{h k l}$ as a function of crystal orientation in orientation space.

For the grains in the central layers of the $\mathrm{Cu}$ foils, they mainly experienced a uniaxial compressive strain. Although the strains in differently oriented grains are slightly different, they are very close (Fig. 7d). Thus, the strain energy should also be dominated by the Young's modulus in the compression direction, i.e., $E^{\prime}{ }_{33}$. We also calculated the $E_{33}^{\prime}$ of all possibly oriented $\mathrm{Cu}$ grains and the obtained orientation-resolved $E_{33}^{\prime}$ represented in the orientation space is displayed in Fig. 11. It is seen that the ${E^{\prime}}_{33}$ is also very anisotropic, varying from $66.70 \mathrm{GPa}$ to $191.27 \mathrm{GPa}$. The lowest $E_{33}^{\prime}(66.70$ $\mathrm{GPa}$ ) is associated with the grains with their $\left\langle 002>_{\mathrm{Cu}}\right.$ parallel to the foil plane normal direction and the highest $E_{33}^{\prime}(191.27 \mathrm{GPa})$ is associated to those with their $<111>_{\mathrm{Cu}}$ parallel to the foil plane normal direction. Thus, in the uniaxial compression (quasi-isostrain) condition, again the grains with the $<002>_{\text {Cu }}$ parallel to the foil plane normal direction or grains with the $\{002\} \mathrm{Cu}$ parallel to the foil plane possess the lowest elastic strain energy and are energetically advantageous to grow. As a result, during the heating process, the growth of the Cube oriented grains was stimulated, as their growth can minimize the elastic strain energy and hence the total energy of the system. These analysis results indeed indicate that the complicated strain state induced by the GNSs provided the unique driving force for the abnormal grain growth of the Cube oriented grains in the $\mathrm{Cu} / \mathrm{GNS}$ composite. 

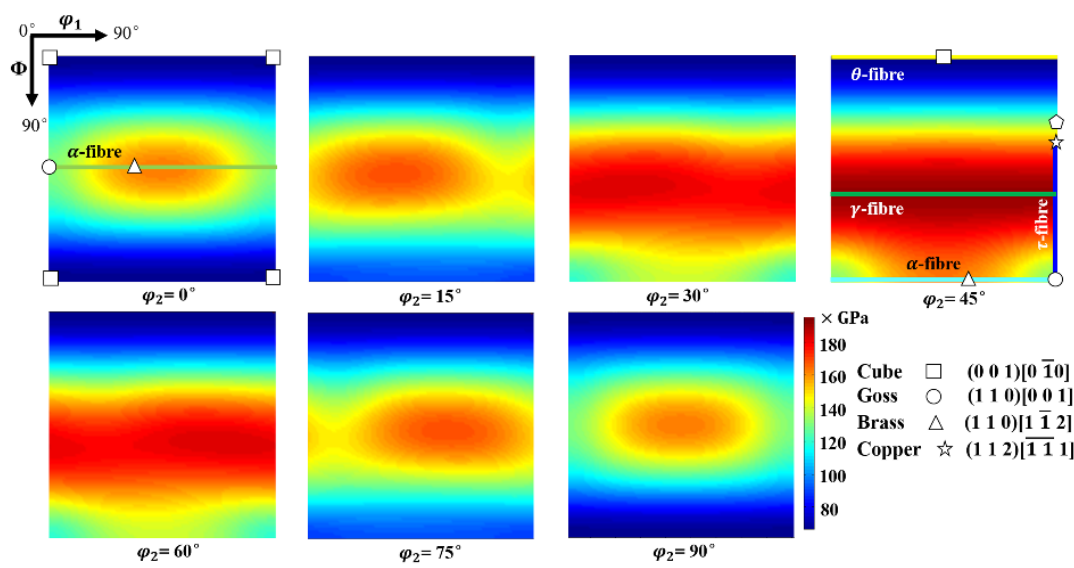

Fig. 11. $\varphi_{2}=0^{\circ}$ to $90^{\circ}$ sections of Young's modulus in the uniaxial compression direction $E_{33}^{\prime}$ as a function of crystal orientation in orientation space.

\section{Summary}

In this study, the complicated elastic strain state of the $\mathrm{Cu}$ matrix induced by the thermal constraints from the GNS reinforcements in the $\mathrm{Cu} / \mathrm{GNS}$ metal/non-metal composite was experimentally investigated through ex-situ and in-situ characterization of microstructure, orientation and lattice strain by means of SEM-EBSD in mesoscale, and neutron diffraction and synchrotron radiation in macroscopic scale. Its selective simulating effect on the specifically oriented grains was quantitatively analyzed by integrated theories of crystallography and elasticity. Its orientation-related potential on orientation selectivity was mapped in the orientation space.

The results revealed that during the heating process of the sintering, the anisotropic and incompatible expansion of the GNS imposed multiple elastic constraints to the $\mathrm{Cu}$ foils. In the surface layers, the $\mathrm{Cu}$ foils mainly experienced a biaxial compressive isostrain parallel to the foil plane, and, in the central layer, they were subjected a uniaxial compressive strain perpendicular to the foil plane. The anisotropic elasticity of $\mathrm{Cu}$ favored the further growth of the Cube oriented grains. The growth of such grains allowed the smallest biaxial modulus planes $\left(\{200\}_{\mathrm{Cu}}\right.$ plane) to be situated in the biaxial isostrain planes and the smallest Young's modulus direction $\left(<200>_{\mathrm{Cu}}\right.$ direction) to be in the uniaxial compression direction, hence minimizing the total strain energy.

The mechanism of elastic strain induced grain growth of selected orientations revealed in the present work provides new information on recrystallization and grain growth of metallic materials and useful for analyzing abnormal grain growth in elastically strained materials, such as the cases in additive fabrication. The orientation related grain growth stimulus can be applied to fabrication process to 
realize texturization or even monocrystallization of metallic materials.

\section{Acknowledgement}

This work was supported by "National Natural Science Foundation of China" (Grant Nos. 51871074, 51971078 and 51671066). This work is based upon experiments in the framework of the proposal No. 13744 performed at the STRESS-SPEC instrument operated by FRM II at the Heinz Maier-Leibnitz Zentrum (MLZ), Garching, Germany. DESY is acknowledged for the provision of synchrotron radiation facilities in the framework of the proposal I-20180861 EC. The research leading to this result has been supported by the project CALIPSOplus under the Grant Agreement 730872 from the EU Framework Programme for Research and Innovation HORIZON 2020. Special thanks to the instrument scientists, Dr. Michael Hofmann at STRESS-SPEC (MLZ) and Dr. Norbert Schell at HEMS (DESY), for their kind assistance during the diffraction experiments at these two institutions and to Dr. Benoit Beausir and Dr. Jean-Jacques Fundenberger at LEM3, Université de Lorraine, for their generous efforts in realizing dedicated application options in their ATEX software package to the orientation and texture analyses in the present work.

\section{Appendix:}

\section{A1. Distribution of deposited GNSs on Cu foil surfaces}

Fig. A1-1 shows the surface morphology micrographs of the raw cold-rolled $\mathrm{Cu}$ foil and the asdeposited GNSs on the $\mathrm{Cu}$ foil surface. The coverage of GNSs on $\mathrm{Cu}$ foil was estimated using the gray levels of the GNSs. The result shows that at least about $40 \%$ of the $\mathrm{Cu}$ surface is covered by the GNSs. It should be mentioned that the determination of the coverage of GNSs is very approximate, as many GNSs are very thin and transparent, as indicated in Fig. A1-1c. This part of GNSs were neglected by the estimation. When the as-deposited Cu-GNS foils were stacked together, the coverage of GNSs should be increased, as the GNSs from the adjacent $\mathrm{Cu}$ foils may fill the uncovered regions of the two foils on the surfaces in contact. 

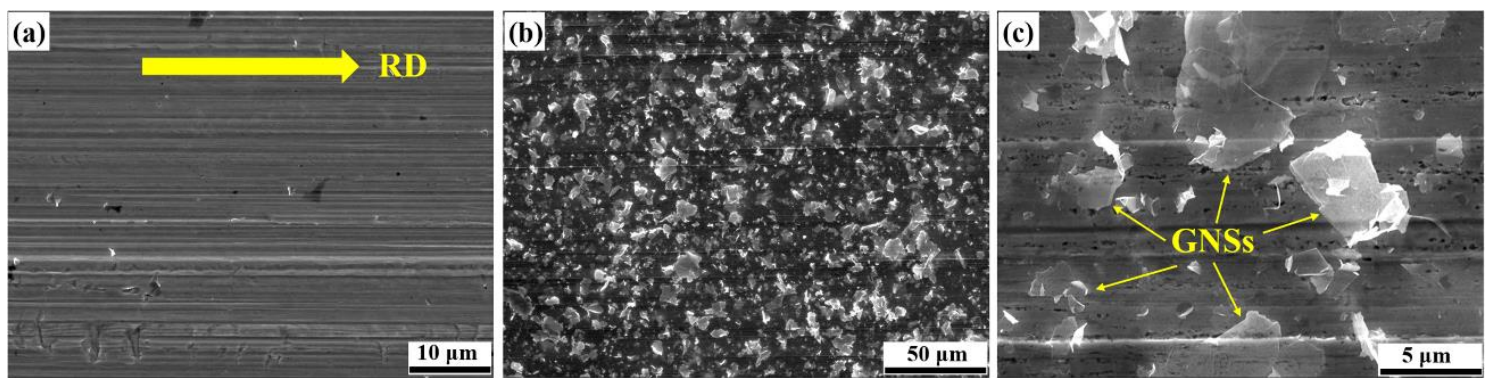

Fig. A1-1. SEM-secondary electron (SE) micrographs of the surface morphology of (a) raw cold-rolled Cu foil, (b) $\mathrm{Cu}$ foil deposited with GNSs (low magnification) and (c) $\mathrm{Cu}$ foil deposited with GNSs (high magnification).

The specification thickness of the purchased GNSs is around $1 \sim 5 \mathrm{~nm}$. This thickness was verified by Atomic Force Microscopy (AFM) analysis. Fig. A1-2a shows an example AFM image of the raw graphene nanosheet (light brown) deposited on a single-crystal silicon substrate (dark brown) from an aqueous dispersion, and Fig. A1-2b the thickness profile along the white line in Fig. A1-2a, starting from the point marked with the green triangle and ending at the point marked with the red triangle. The average thickness of the GNS is about $3.85 \mathrm{~nm}$ that is consistent with the specification thickness of the purchased GNSs.
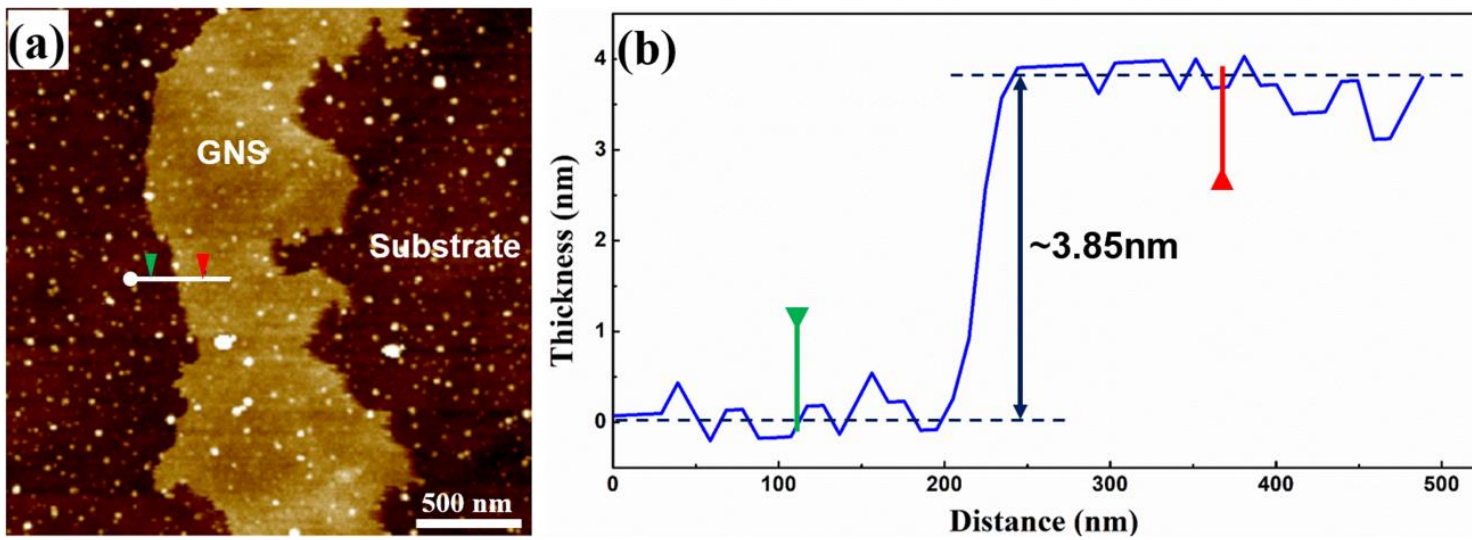

Fig. A1-2. (a) AFM image of raw graphene nanosheet deposited on a single-crystal silicon substrate; (b) the corresponding thickness profile along the white line in (a).

\section{A2. Tensor expression used in this work}

Matrix expression of Eq. (2) in Nye's notation [46]:

$$
\left[\begin{array}{l}
\sigma_{11} \\
\sigma_{22} \\
\sigma_{33} \\
\sigma_{23} \\
\sigma_{13} \\
\sigma_{12}
\end{array}\right]=\left[\begin{array}{llllll}
C_{1111} & C_{1122} & C_{1133} & C_{1123} & C_{1113} & C_{1112} \\
C_{2211} & C_{2222} & C_{2233} & C_{2223} & C_{2213} & C_{2212} \\
C_{3311} & C_{3322} & C_{3333} & C_{3323} & C_{3313} & C_{3312} \\
C_{2311} & C_{2322} & C_{2333} & C_{2323} & C_{2313} & C_{2312} \\
C_{1311} & C_{1322} & C_{1333} & C_{1323} & C_{1313} & C_{1312} \\
C_{1211} & C_{1222} & C_{1233} & C_{1223} & C_{1213} & C_{1212}
\end{array}\right] \cdot\left[\begin{array}{c}
\varepsilon_{11} \\
\varepsilon_{22} \\
\varepsilon_{33} \\
\varepsilon_{23} \\
\varepsilon_{13} \\
\varepsilon_{12}
\end{array}\right]
$$

For cubic crystals, Eq. (A1) is in the following form: 


$$
\left[\begin{array}{l}
\sigma_{11} \\
\sigma_{22} \\
\sigma_{33} \\
\sigma_{23} \\
\sigma_{13} \\
\sigma_{12}
\end{array}\right]=\left[\begin{array}{cccccc}
C_{11} & C_{12} & C_{12} & 0 & 0 & 0 \\
C_{12} & C_{11} & C_{12} & 0 & 0 & 0 \\
C_{12} & C_{12} & C_{11} & 0 & 0 & 0 \\
0 & 0 & 0 & C_{44} & 0 & 0 \\
0 & 0 & 0 & 0 & C_{44} & 0 \\
0 & 0 & 0 & 0 & 0 & C_{44}
\end{array}\right] \cdot\left[\begin{array}{c}
\varepsilon_{11} \\
\varepsilon_{22} \\
\varepsilon_{33} \\
\varepsilon_{23} \\
\varepsilon_{13} \\
\varepsilon_{12}
\end{array}\right]
$$

\section{Reference}

[1] M.H. Alvi, S.W. Cheong, J.P. Suni, H. Weiland, A.D. Rollett, Cube texture in hot-rolled aluminum alloy 1050 (AA1050) — nucleation and growth behavior, Acta Mater., 56(13) (2008) 3098-3108.

[2] Y. Lü, D.A. Molodov, G. Gottstein, Recrystallization kinetics and microstructure evolution during annealing of a cold-rolled Fe-Mn-C alloy, Acta Mater., 59(8) (2011) 3229-3243.

[3] L.A.I. Kestens, H. Pirgazi, Texture formation in metal alloys with cubic crystal structures, Mater. Sci. Technol., 32(13) (2016) 1303-1315.

[4] J. Humphreys, G.S. Rohrer, A.D. Rollett, Recrystallization and Related Annealing Phenomena, third ed., Elsevier, (2017).

[5] B. Lin, Y. Jin, C.M. Hefferan, S.F. Li, J. Lind, R.M. Suter, M. Bernacki, N. Bozzolo, A.D. Rollett, G.S. Rohrer, Observation of annealing twin nucleation at triple lines in nickel during grain growth, Acta Mater., 99 (2015) 63-68.

[6] R. Carel, C.V. Thompson, H.J. Frost, Computer simulation of strain energy effects vs furface and interface energy effects on grain growth in thin films, Acta Mater., 44 (1995) 2479-2494.

[7] E.M. Zielinski, R.P. Vinci, J.C. Bravman, The influence of strain energy on abnormal grain growth in copper thin films, Appl. Phys. Lett., 67(8) (1995) 1078-1080.

[8] J.M. Zhang, K.W. Xu, V. Ji, Competition between surface and strain energy during grain growth in free-standing and attached Ag and Cu films on Si substrates, Appl. Surf. Sci. 187 (2002) 60-67.

[9] D.-U. Kim, P.-R. Cha, S.G. Kim, W.T. Kim, J. Cho, H.-N. Han, H.-J. Lee, J. Kim, Effect of microelasticity on grain growth and texture evolution: A phase field grain growth simulation, Comput. Mater. Sci., 56 (2012) 58-68.

[10] D. Fabregue, B. Mouawada, C.R. Hutchinson, Enhanced recovery and recrystallization of metals due to an applied current, Scr. Mater., 92 (2014) 3-6. 
[11] Z. Sun, P.D. Edmondson, Y. Yamamoto, Effects of Laves phase particles on recovery and recrystallization behaviors of Nb-containing FeCrAl alloys, Acta Mater., 144 (2018) 716-727.

[12] D.G. Cram, H.S. Zurob, Y.J.M. Brechet, C.R. Hutchinson, Modelling discontinuous dynamic recrystallization using a physically based model for nucleation, Acta Mater., 57 (2009) 5218-5228.

[13] C.S.T. Chang, B.J. Duggan, Relationships between rolled grain shape, deformation bands, microstructures and recrystallization textures in Al-5\%Mg, Acta Mater., 58(2) (2010) 476-489.

[14] P. Chekhonin, B. Beausir, J. Scharnweber, C.-G. Oertel, T. Hausöl, H.W. Höppel, H.-G. Brokmeier, W. Skrotzki, Confined recrystallization of high-purity aluminium during accumulative roll bonding of aluminium laminates, Acta Mater., 60(11) (2012) 4661-4671.

[15] M.M. Miszczyk, H. Paul, J.H. Driver, J. Poplewska, The influence of deformation texture on nucleation and growth of cube grains during primary recrystallization of AA1050 alloy, Acta Mater., 129 (2017) 378-387.

[16] B.J. Duggan, M. Sindel, C.D. Kohlhoff, K. Lucke, Oriented nucleation, oriented growth and twinning in cube texture formation, Acta Metall. Mater., 38 (1990) 103-111.

[17] O. Engler, H.E. Vatne, E. Nes, The roles of oriented nucleation and oriented growth on recrystallization in commercial purity aluminium, Mater. Sci. Eng. A, 205 (1996) 187-198.

[18] G.H. Fan, Y.B. Zhang, J.H. Driver, D. Juul Jensen, Oriented growth during recrystallization revisited in three dimensions, Scr. Mater., 72-73 (2014) 9-12.

[19] J.S. Carpenter, T. Nizolek, R.J. McCabe, M. Knezevic, S.J. Zheng, B.P. Eftink, J.E. Scott, S.C. Vogel, T.M. Pollock, N.A. Mara, I.J. Beyerlein, Bulk texture evolution of nanolamellar Zr-Nb composites processed via accumulative roll bonding, Acta Mater., 92 (2015) 97-108.

[20] R.J. McCabe, J.S. Carpenter, S. Vogel, N.A. Mara, I.J. Beyerlein, Recrystallization and Grain Growth in Accumulative Roll-Bonded Metal Composites, JOM, 67(12) (2015) 2810-2819.

[21] J. Scharnweber, P. Chekhonin, C.-G. Oertel, J. Romberg, J. Freudenberger, J. Jaschinski, W. Skrotzki, Microstructure, texture, and mechanical properties of laminar metal composites produced by accumulative roll bonding, Adv. Eng. Mater., 21(1) (2019) 1800210.

[22] L. Battezzati, C. Antonione, F. Fracchia, Ni-Al intermetallics produced by cold-rolling elemental sheets, Intermetallics, 3 (1995) 67-71. 
[23] W.C. Crone, A.N. Yahya, J.H. Perepezko, Bulk shape memory NiTi with refined grain size synthesized by mechanical alloying, Mater. Sci. Forum, 386 (2002) 597-602.

[24] J.J. Williams, Z. Flom, A.A. Amell, N. Chawla, X. Xiao, F. De Carlo, Damage evolution in SiC particle reinforced Al alloy matrix composites by X-ray synchrotron tomography, Acta Mater., 58 (2010) 6194-6205.

[25] K. Kawabata, E. Sato, K. Kuribayashi, Creep deformation behavior of spherical $\mathrm{Al}_{2} \mathrm{O}_{3}$ particlereinforced Al-Mg matrix composites at high temperatures, Acta Mater., 50 (2002) 3465-3474.

[26] C. Schuh, D.C. Dunand, Whisker alignment of Ti-6Al-4V/TiB composites during deformation by transformation superplasticity, Int. J. Plast., 17 (2001) 317-340.

[27] T. Okabe, N. Takeda, J. Komotori, M. Shimizu, W. A. Curtin, A new fracture mechanics model for multiple matrix cracks of SiC fiber reinforced brittle-matrix composites, Acta Mater., 47(17) (1999) 4299-4309.

[28] T. Liu, X. Tian, Y. Zhang, Y. Cao, D. Li, High-pressure interfacial impregnation by micro-screw in-situ extrusion for 3D printed continuous carbon fiber reinforced nylon composites, Composites, Part A, $130(2020) 105770$.

[29] S. Sherman, J. Simmons, C. Przybyla, Mesoscale characterization of continuous fiber reinforced composites through machine learning: Fiber chirality, Acta Mater., 181 (2019) 447-459.

[30] G. Fan, Y. Jiang, Z. Tan, Q. Guo, D.-b. Xiong, Y. Su, R. Lin, L. Hu, Z. Li, D. Zhang, Enhanced interfacial bonding and mechanical properties in CNT/Al composites fabricated by flake powder metallurgy, Carbon, 130 (2018) 333-339.

[31] Q.-h. Yuan, G.-h. Zhou, L. Liao, Y. Liu, L. Luo, Interfacial structure in AZ91 alloy composites reinforced by graphene nanosheets, Carbon, 127 (2018) 177-186.

[32] B. Beausir, J.-J. Fundenberger, Analysis Tools for Electron and X-ray diffraction, ATEX - software Universite de Lorraine - Metz (2017). http://www.atex-software.eu

[33] C. Randau, U. Garbe, H.G. Brokmeier, StressTextureCalculator: a software tool to extract texture, strain and microstructure information from area-detector measurements, J. Appl. Crystallogr., 44(3) (2011) 641-646.

[34] N. Schell, A. King, F. Beckmann, T. Fischer, M. Mueller, A. Schreyer, The High Energy Materials Science Beamlime (HEMS) at PETRA III. Mater. Sci. Forum, 772 (2014) 57-61. 
[35] A.P. Hammersley, S.O. Svensson, M. Hanfland, A.N. Fitch, D. Hausermann, Two-dimensional detector software: From real detector to idealised image or two-theta scan, High Pressure Res., 14(46) (1996) 235-248.

[36] E.E. Villalobos-Portillo, D.C. Burciaga-Valencia, L. Fuentes-Montero, M.E. Montero-Cabrera, D. Chateigner, L.E. Fuentes-Cobas, Texture, 2D diffraction and piezoelectricity, Boletín de la Sociedad Española de Cerámicay Vidrio (2020).

[37] L. Lutterotti, Matthies, MAUD - Materials Analysis Using Diffraction, http://maud.radiographema.com/.

[38] D. Chateigner, L. Lutterotti, M. Morales, Quantitative texture analysis and combined analysis, International Tables for Crystallography John Wiley \& Sons, London, UK, Vol. H, Chapter 5.3 (2019) $555-580$.

[39] D. Chateigner, Combined Analysis, John wiley \& Sons, London, UK (2013).

[40] H.J. Bunge, C. Esling and J. Muller, The influence of crystal and sample symmetries on the orientation distribution function of the crystallites in polycrystalline materials, Acta Cryst., A37 (1981) 889-899.

[41] T. Adler, C.R. Houska, Simplifications in the x-ray line-shape analysis, J. Appl. Phys., 50(5) (1979) $3282-3287$.

[42] A. Leineweber, E.J. Mittemeijer, Notes on the order-of-reflection dependence of microstrain broadening, J. Appl. Crystallogr., 43(5) (2010) 981-989.

[43] Z.H. Ni, H.M. Wang, J. Kasim, H.M. Fan, T. Yu, Y.H. Wu, Y.P. Feng, Z.X. Shen, Graphene Thickness Determination Using Reflection and Contrast Spectroscopy, Nano Lett., 7(9) (2007) 27582763.

[44] K. Wang, R.R. Reeber, Thermal Expansion of Copper, High Temp. Mater. Sci., 35 (1996) 184185 .

[45] N. Mounet, N. Marzari, First-principles determination of the structural, vibrational and thermodynamic properties of diamond, graphite, and derivatives, Phys. Rev. B, 71(20) (2005) 205214. [46] J.F. Nye, Physical properties of crystals, University Press, Oxford, (1972) 131.

[47] K.M. Knowles, The Biaxial Moduli of Cubic Materials Subjected to an Equi-biaxial Elastic Strain, 
Journal of Elasticity, 124(1) (2016) 1-25.

[48] H.J. Bunge, C. Esling and J. Muller, The role of the inversion centre in texture analysis, J. Appl. Cryst., 13 (1980) 544-554. 